Sharif University of Technology
Scientia Iranica
Transactions E: Industrial Engineering
http://scientiairanica.sharif.edu
IRAN ICA

\title{
Efficient scheduling of emergency surgeries by adjusting the schedule of elective surgeries
}

\author{
M. Yazdi ${ }^{a}$, M. Zandieh ${ }^{b, *}$, H. Haleh ${ }^{\text {, }}$, and S.H.R. Pasandideh ${ }^{\text {d }}$ \\ a. Department of Industrial Engineering, Faculty of Industrial and Mechanical Engineering, Qazvin Branch, Islamic Azad \\ University, Qazvin, Iran. \\ b. Department of Industrial Management and Information Technology, Faculty of Management and Accounting, Shahid Beheshti \\ University, Tehran, Iran. \\ c. Faculty of Industrial Engineering, Golpayegan University of Technology, Golpayegan, Iran. \\ d. Department of Industrial Engineering, Faculty of Engineering, Kharazmi University, Tehran, Iran.
}

Received 2 June 2019; received in revised form 30 November 2020; accepted 8 March 2021

\section{KEYWORDS}

Surgery scheduling; Operating rooms;

Emergency surgery;

Break-in-moments;

Project scheduling.

\begin{abstract}
The rapid population growth has resulted in ever-growing demand for healthcare services, which forces managers to use costly resources such as operating rooms effectively. The surgery-scheduling problem is a general title that is attributed to such problems as patient selection and sequencing of surgeries at the operational level, setting their start times, and assigning resources. Hospital managers usually encounter elective surgeries that can be delayed slightly and emergency surgeries whose arrivals are unexpected, and most of them need quick access to operating rooms. Reserving operating room capacity for handling incoming emergency surgeries is expensive. Moreover, emergency surgeries cannot afford long waiting times. This paper deals with the problem of surgery scheduling in the presence of emergency surgeries with a focus on balancing the efficient use of operating room capacity and responsiveness to emergency surgeries. We proposed a new algorithm for surgery scheduling with a specific operating room capacity planning and analyzed it using simulation method based on real data. This algorithm respects working hours and availability of staff and other resources in a surgical suite.
\end{abstract}

(C) 2023 Sharif University of Technology. All rights reserved.

\section{Introduction}

Most of the hospital revenues and expenditures result from Operating Rooms (ORs) which represent the heart of hospitals. Due to the expenses associated with ORs, their efficient use in surgery scheduling is considerable. The quality of surgery scheduling directly affects waiting times and admission or rejection of patients since it has a crucial role in maintaining

*. Corresponding author. Tel.: +982129905215 E-mail address: M_zandiyeh@sbu.ac.ir (M. Zandieh)

doi: $10.24200 /$ sci. 2021.53630 .3339 patient health. Moreover, the work lives of surgeons, anesthesiologists, nurses, and other OR staff are also affected by how a schedule distributes staff workload.

The OR management consists of many decisions in OR capacity planning and scheduling. Some of these decisions from the viewpoint of the hierarchical pyramid of decision-making are strategic decisions (longterm), tactical decisions (medium-term), and operational decisions (short-term) [1]. Strategic decisions or case-mix planning initiate with demand forecasting for the long term. According to this forecasting, some surgery specialties (such as cardiothoracic surgery and neurological surgery) are selected for patient admission. Furthermore, the amount of OR capacity acquisition 
is determined. How many ORs to be constructed is based on a very long-term (one to five years) demand estimation. Which surgical specialties to be served is based on long-term (6 months to one year) estimation [2]. Decision-making about how to divide the OR capacities among these specialties (OR time blocks) is part of the tactical decision-making. The mediumterm demand forecasting influences OR time blocks [2]. These problems are known as master surgical scheduling in the literature. The OR time blocks determine the time duration and the amount of OR capacity that are accessible for patients from each surgery specialty. Finally, patient selection and sequencing of the surgeries, determination of their start times, and resource allocation in surgery cases are the problems at the operational level $[3,4]$. The scope of this paper is only limited to the Surgery Scheduling Problem (SSP) at the operational level. This means that only surgery requests for some surgery specialties are admitted and the determination of surgery specialties that should be selected for providing service to patients is not within the scope of this research. Moreover, the OR time blocks that divide the OR capacity among surgery specialties are given and their determination is beyond the scope of our work. In this paper, we encounter the problem of determining a sequence of patient surgeries, assigning proper resources to them, and setting their start times. These patient surgeries require various specialties and by the same logic, the corresponding resources are of various types (ORs, surgeons, recovery rooms, staff, and so on) and are available based on working hours and OR time blocks

\subsection{Elective and emergency surgeries}

Hospitals consider the scheduling of two classes of elective and emergency surgeries. Elective surgeries are related to patients who are admitted a few days ago. On the contrary, emergency surgeries have specific characteristics: their occurrences are unexpected and often during the execution of the schedule of other surgeries. Moreover, emergency surgeries generally require quick access to ORs [5]. Handling emergency surgeries is a complicated task for hospital managers. These surgeries often have high urgency. Sometimes, emergency surgeries need immediate access to an OR, but most of them can afford some waiting time. The amount of the tolerable waiting time for an emergency patient depends on the severity and kind of illness. Emergency surgeries can arise 24/7. The stochastic nature of emergency surgeries and their threats to patients' lives force managers to reserve resources at a certain capacity to handle emergency surgeries, which lead to particular resource planning.

Performing patient surgery needs access to multiple expensive resources such as OR and professionals simultaneously. This necessity clarifies the difficulties of surgery scheduling in case of emergency surgeries. Furthermore, the arrival of emergency surgeries may disturb the prescheduled surgeries, causing instability in staffing and shift scheduling in surgical suites. Besides, it causes reorganizing resources in surgical suites and even sometimes in other upstream and downstream units at hospitals [6]. Hospitals usually ask on-call surgery teams to attend within thirty minutes, and the problem of availability of professionals is dealt with in this way. Managers concern themselves about the OR capacity planning for handling emergency surgeries better.

\subsection{Various OR capacity planning}

In fact, creating a balance between responsiveness for saving the lives of emergency patients and effective utilization of expensive resources such as ORs is a challenge that every hospital manager encounters. Only a limited number of previous papers have dealt with the subject of emergency surgery scheduling $[7,8]$. Flexible ORs and dedicated ORs are two main OR capacity planning for encountering emergency surgeries that have been examined in the literature. In the flexible ORs policy, OR capacity is shared between elective and emergency surgeries. This OR policy can result in disruptions during the execution of the scheduled tasks and lead to higher waiting times and the cost of using resources overtime [9]. In order to avoid these disruptions, a dedicated OR policy is suggested in the literature $[10,11]$. In the dedicated OR policy, ORs are divided into two separate groups. Each group of elective and emergency surgeries only can be scheduled in their ORs. This policy prevents disruptions from the arrival of emergency surgeries, but OR utilization is the drawback and it is a costly method $[9,12]$. Dedicated ORs to emergency surgeries are never used by elective surgeries even when they are free for a long time, and many elective surgeries experience longer waiting times. "How to divide ORs capacity between emergency and elective surgeries" is an important question, which is dealt with in some papers like Persson and Persson [13]. The selection of each OR policy can influence the efficiency of the resulting schedule. Furthermore, the selected OR policy affects the number of schedule disruptions and the amount of OR utilization [12].

As mentioned before, all the ORs are utilized for both elective and emergency surgeries in flexible OR policy. The authors apply different approaches to implementing flexible ORs policy. In the first category of papers, some fraction of OR time is reserved for inserting emergency surgeries. This fraction of OR time can be considered as an integrated timespace of OR availability interval or as various shorter slack times between elective surgeries in the schedule. These approaches utilize OR capacity partitioning 
to handle emergency surgeries [9]. In some others, scheduling of elective surgeries is done without any prior time allocation for emergency surgeries. In this approach, emergency surgery can be inserted in any free slack or replaced with elective surgeries in the schedule at moments when elective surgeries are expected to finish. This approach partitions OR capacities between elective and emergency surgeries in real time [9]. Consequently, the implementation of this approach is more complicated than the former category. The terminology of Break-In-Moment (BIM) is the potential start times of emergency surgeries or the equivalent finish times of elective surgeries [14]. Indeed, scheduling elective surgeries in this approach is done by concentrating on spreading the BIMs at OR intervals to reduce waiting times in emergency surgeries.

Figure 1 clarifying the insertion of an emergency surgery into the schedule of elective surgeries in three ORs. The OR policy is flexible, and emergency surgery is inserted to be scheduled at BIMs.

The BIMs approach is implemented in a few papers. This approach was introduced by Van Essen et al. [14]. Vandenberghe et al. extended the BIMs approach to cases where surgery durations are stochastic with known distributions [15]. Duma and Aringhieri also used the BIMs approach in their paper [16]. Another recent work proposes a combination of dedicated and flexible ORs (hybrid policy) in which some rooms are dedicated strictly to elective surgeries or emergency surgeries, while others are flexible to serve both of them [17].

Each of the previous OR policies (dedicated, flexible, and their subgroups) is utilized in the literature. The question about "which of these policies is better in a specific scenario" has no strict answer and strongly depends on the hospital conditions and other operational conditions [16].

\subsection{The SSP in the literature review}

Many researchers from the operation research community have expressed interests in the SSP, also named as OR scheduling problem. Plenty of the SSP works have been presented in the recent review papers $[1,3,18,19]$. Generally, the number of SSP articles has significantly increased in the current decade [18]. Moreover, recent studies on SSP have tended to solve complicated problems [19].

In the literature, the authors consider SSP from different points of view. Pham and Klinkert supposed a flow of patients that moves through some hospital units. They have formulated the SSP as a generalized job shop-scheduling problem [20]. Van Essen et al. provided a decision support system that constructed schedules by considering patients and wards desirability as different stakeholders of the SSP [21]. Jung et al. considered a class of parallel machines scheduling for the SSP [22]. Aringhieri et al. covered the demands of some patients for surgery over the weekends and considered both the OR time blocking problem and the SSP together [23]. Moosavi and Ebrahimnejad considered the SSP when unscheduled surgeries defer to the next scheduling period [24]. Riise et al. supposed any patient surgery as a project, which consisted of several activities. The execution of any activity requires some sets of resources (modes). Each resource can be available with a predefined capacity at some time intervals [25]. They proposed a multi-project, multimode resource-constrained project-scheduling problem

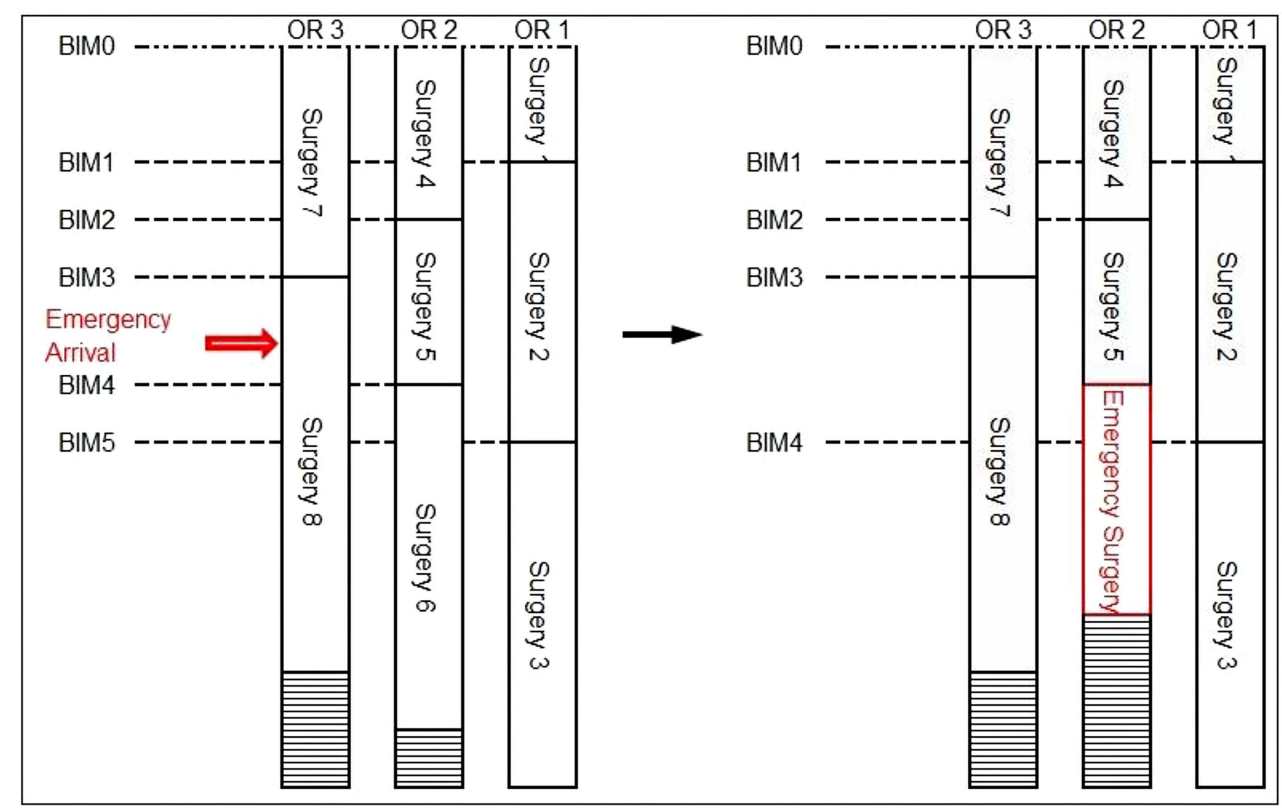

Figure 1. Scheduling of elective and emergency surgeries under the BIM policy. 
with generalized precedence relations for the SSP. The authors classified this problem as an NP-hard problem with reference to Hans et al. [26] and developed the Generalized Operational Surgery-Scheduling Problem (GOSSP), which is a meta-heuristic algorithm for this problem. Santibáñez et al. focused on the interrelation master surgical scheduling and the feasibility of the schedules. The authors mentioned that because some post-surgical resources such as recovery rooms were limited and shared by all the patients, their capacity can make an OR time block impossible. They considered both of the problems (master surgical scheduling and scheduling of the patients at the operational level) jointly to create a feasible OR time block. They defined surgical groups in each surgery specialty. These surgical groups have the same resource requirements and consist of the same procedures. Then, they concentrated on scheduling surgical groups instead of scheduling surgeries [27]. The utilization of surgical groups was developed by Banditori et al. by adding the patient's due dates and durations. The authors utilized mixed-integer programming and simulation methods and suggested an approach to determine which surgical specialties can serve in the ORs and determine OR time blocks in the surgery suite. In doing so, they solve strategic and tactical planning problems jointly [28]. Cappanera et al. integrated master surgical scheduling with patient selection and sequencing problems and developed a multi-objective mixed-integer programming model [29]. Visintin et al. considered the master surgical scheduling problem jointly with managing some critical resources (surgical teams, ORs, and surgical units) [30]. Table 1 reports the main characteristics of some recent literature in the SSP.

\subsection{Contributions}

To our best knowledge, only Riise et al. [25,31] utilized "a multi-project multi-mode resource-constrained project-scheduling problem with generalized precedence relations" as the optimization model for the SSP. Moreover, the implementation of the BIMs idea has only been addressed in few papers and is yet not fully explored in the literature. Riise et al. merely focused on elective surgery scheduling in their works $[25,31]$ and as a result, all the ORs were dedicated to elective surgeries. In this paper, we consider emergency surgeries to extend their work. Furthermore, to handle emergency surgeries, we consider the flexible OR policy and implement the idea of BIMs to attend to emergency surgeries.

One of the difficulties of the SSP comes from uncertainty, such as the patient's arrival uncertainty, duration's uncertainty, and failure of critical medical equipment [19]. In this paper, we ignore the equipment failure and the unpredictability of elective patient's arrival. As mentioned by Riise et al., for dealing with the deviation of the duration time of surgeries, many hospitals use estimations [25]. Therefore, we assume that after any surgery referral (elective surgery or emergency surgery), an expert estimates all the possible modes for the activities. The expert estimates a duration for any activity in any mode based on his or her prior experiences. These estimations help us to deal with uncertainty in the durations which comes from the difference between various resources.

The rest of this paper is structured as follows. Section 2 provides an overview of the problem definitions, and Section 3 discusses the proposed algorithm. Section 4 illustrates experimental designs and some computational experiments. Finally, Section 5 addresses conclusions and some outlines for future works.

\section{Problem description}

This paper is an attempt at scheduling a set $P$ of patient surgeries with some specialties such as cardiothoracic surgery, neurological surgery, and so on. These surgical specialties have been previously determined, and the determination of them is not within our scope. Initially, this set only contains elective surgeries, but during the execution of the schedule, the set changes to include some emergency surgeries. Performing a patient surgery needs allocating more than one resource type simultaneously.

\subsection{Resources}

The patient surgeries in the set $P$ use a shared set of resources $R$ that includes various resource types such as ORs, surgeons, etc. Any resource in $R$ has a particular working hour or availability interval, and this resource is only available at these hours in some capacities. Any resource $\forall r \in R$ has a set of non-overlapping availability intervals $K^{r}=\left\{k_{1}, k_{2}, \ldots\right\}$ in which $k_{q} \in$ $K^{r}$ refers to one of the availability intervals with the capacity $c_{q}$. This way of representing the availability of resources helps us consider a continuous-time model for representing the availability and capacity of resources $[25,31]$.

The ORs are available for each surgery specialty according to the master surgical planning (OR time blocks). In other words, each time interval $k_{q}$ in any OR can only be assigned to a specific surgery specialty (see Figure 2).

It is assumed that the resources availability intervals, resource capacities at each availability interval, and OR time blocks are known and given. It is supposed that the restrictions, which come from OR time block, only apply to elective surgeries. However, emergency surgeries can use any OR available interval without considering the OR time blocks.

\subsection{Activities and activity modes}

Performing each patient surgery $\forall p \in P$ consists of 
Table 1. The main characteristics of SSP in recent literature.

\begin{tabular}{|c|c|c|c|c|c|c|c|c|}
\hline \multirow[b]{3}{*}{ Authors } & \multicolumn{6}{|c|}{ OR capacity configuration } & \multirow[b]{3}{*}{$\begin{array}{l}\text { Solution } \\
\text { technique }\end{array}$} & \multirow[b]{3}{*}{$\begin{array}{c}\text { Optimization } \\
\text { model } \\
\text { formulation }\end{array}$} \\
\hline & \multicolumn{2}{|c|}{ Patient classification } & \multicolumn{3}{|c|}{ Flexible ORs } & \multirow[b]{2}{*}{$\begin{array}{l}\text { Partially } \\
\text { flexible } \\
\text { ORs }\end{array}$} & & \\
\hline & Elective & Emergency & $\begin{array}{c}\text { Dedicated } \\
\text { ORs }\end{array}$ & $\begin{array}{l}\text { Reserved } \\
\text { spaces } \\
\text { or slacks }\end{array}$ & $\begin{array}{c}\text { BIMs } \\
\text { adjustment }\end{array}$ & & & \\
\hline Ferrand et al. (2014) & $\sqrt{ }$ & $\sqrt{ }$ & $\sqrt{ }$ & $\sqrt{ }$ & & $\sqrt{ }$ & Simulation & \\
\hline Duma and Aringhieri (2018) & $\sqrt{ }$ & $\sqrt{ }$ & & & $\sqrt{ }$ & & Simulation & $\begin{array}{l}\text { Real time } \\
\text { management } \\
\text { model }\end{array}$ \\
\hline Duma and Aringhieri (2015) & $\sqrt{ }$ & $\sqrt{ }$ & $\sqrt{ }$ & $\sqrt{ }$ & & & $\begin{array}{c}\text { Hybrid simulation } \\
\text { and optimization } \\
\text { method }\end{array}$ & $\begin{array}{l}\text { Real time } \\
\text { management } \\
\text { model }\end{array}$ \\
\hline Jung et al. (2019) & $\sqrt{ }$ & $\sqrt{ }$ & & & $\sqrt{ }$ & & $\begin{array}{l}\text { Hybrid heuristics } \\
\text { and mixed } \\
\text { integer programming }\end{array}$ & $\begin{array}{l}\text { Mixed integer } \\
\text { programming }\end{array}$ \\
\hline Banditori et al. (2013) & $\sqrt{ }$ & & $\sqrt{ }$ & & & & $\begin{array}{c}\text { Hybrid simulation } \\
\text { and mixed integer } \\
\text { programming }\end{array}$ & $\begin{array}{l}\text { Mixed integer } \\
\text { programming }\end{array}$ \\
\hline $\begin{array}{l}\text { Van Essen } \\
\text { et al. }(2012 \text { a) }[21]\end{array}$ & $\sqrt{ }$ & $\sqrt{ }$ & & $\sqrt{ }$ & & & $\begin{array}{l}\text { Hybrid simulation } \\
\text { and optimization } \\
\text { method }\end{array}$ & $\begin{array}{l}\text { Mixed integer } \\
\text { programming }\end{array}$ \\
\hline $\begin{array}{l}\text { Van Essen } \\
\text { et al. }(2012 \text { b) [14] }\end{array}$ & $\sqrt{ }$ & $\sqrt{ }$ & & & $\sqrt{ }$ & & $\begin{array}{l}\text { Hybrid simulation, } \\
\text { heuristics and } \\
\text { mixed integer } \\
\text { programming }\end{array}$ & $\begin{array}{l}\text { Mixed integer } \\
\text { programming }\end{array}$ \\
\hline Hans et al. (2008) & $\sqrt{ }$ & & & $\sqrt{ }$ & & & $\begin{array}{l}\text { Hybrid simulation } \\
\text { and heuristic }\end{array}$ & $\begin{array}{c}\text { Stochastic knapsack } \\
\text { problem }\end{array}$ \\
\hline $\begin{array}{c}\text { Moosavi \& } \\
\text { Ebrahimnejad (2018) }\end{array}$ & $\sqrt{ }$ & $\sqrt{ }$ & $\sqrt{ }$ & & & & $\begin{array}{c}\text { Hybrid Mixed } \\
\text { Integer Programming } \\
\text { and heuristic }\end{array}$ & $\begin{array}{l}\text { Mathematical } \\
\text { programming }\end{array}$ \\
\hline Cappanera et al. (2016) & $\sqrt{ }$ & & $\sqrt{ }$ & & & & $\begin{array}{l}\text { Mixed integer } \\
\text { programming }\end{array}$ & $\begin{array}{c}\text { Goal } \\
\text { programming }\end{array}$ \\
\hline Litvak et al. (2008) & $\sqrt{ }$ & $\sqrt{ }$ & & $\sqrt{ }$ & & & $\begin{array}{c}\text { Equivalent random } \\
\text { method over } \\
\text { simulation }\end{array}$ & $\begin{array}{c}\text { Overflow models } \\
\text { in telecommunication } \\
\text { systems }\end{array}$ \\
\hline $\begin{array}{l}\text { Lamiri et al. } \\
\text { (2008)-stochastic }\end{array}$ & $\sqrt{ }$ & $\sqrt{ }$ & & $\sqrt{ }$ & & & $\begin{array}{l}\text { Hybrid simulation } \\
\text { and mixed } \\
\text { integer programming }\end{array}$ & $\begin{array}{l}\text { Stochastic } \\
\text { mathematical } \\
\text { programming }\end{array}$ \\
\hline Persson \& Persson (2010) & $\sqrt{ }$ & $\sqrt{ }$ & & $\sqrt{ }$ & & & Simulation & $\begin{array}{l}\text { Bin packing } \\
\text { model }\end{array}$ \\
\hline Pham \& Klinkert (2008) & $\sqrt{ }$ & $\sqrt{ }$ & & $\sqrt{ }$ & & & $\begin{array}{l}\text { Hybrid simulation } \\
\text { and mixed } \\
\text { integer programming }\end{array}$ & $\begin{array}{l}\text { Generalized } \\
\text { job shop } \\
\text { scheduling } \\
\text { problem }\end{array}$ \\
\hline Santibáñez et al. (2007) & $\sqrt{ }$ & $\sqrt{ }$ & & $\sqrt{ }$ & & & $\begin{array}{l}\text { Hybrid simulation } \\
\text { and mixed } \\
\text { integer } \\
\text { programming }\end{array}$ & $\begin{array}{l}\text { Mixed integer } \\
\text { programming }\end{array}$ \\
\hline Tancrez et al. (2013) & $\sqrt{ }$ & $\sqrt{ }$ & $\sqrt{ }$ & $\sqrt{ }$ & & & Simulation & Markovian model \\
\hline Tancrez et al. (2009) & $\sqrt{ }$ & $\sqrt{ }$ & $\sqrt{ }$ & $\sqrt{ }$ & & & Simulation & Markovian model \\
\hline
\end{tabular}


Table 1. The main characteristics of SSP in recent literature (continued).

\begin{tabular}{|c|c|c|c|c|c|c|c|c|}
\hline \multirow[b]{3}{*}{ Authors } & \multicolumn{6}{|c|}{ OR capacity configuration } & \multirow[b]{3}{*}{$\begin{array}{l}\text { Solution } \\
\text { technique }\end{array}$} & \multirow[b]{3}{*}{$\begin{array}{l}\text { Optimization } \\
\text { model } \\
\text { formulation }\end{array}$} \\
\hline & \multicolumn{2}{|c|}{ Patient classification } & \multicolumn{3}{|c|}{ Flexible ORs } & \multirow[b]{2}{*}{$\begin{array}{l}\text { Partially } \\
\text { flexible } \\
\text { ORs }\end{array}$} & & \\
\hline & Elective & Emergency & $\begin{array}{c}\text { Dedicated } \\
\text { ORs }\end{array}$ & $\begin{array}{l}\text { Reserved } \\
\text { spaces } \\
\text { or slacks }\end{array}$ & $\begin{array}{c}\text { BIMs } \\
\text { adjustment }\end{array}$ & & & \\
\hline Vandenberghe et al. (2019) & $\sqrt{ }$ & $\sqrt{ }$ & & & $\sqrt{ }$ & & $\begin{array}{l}\text { Hybrid simulation } \\
\text { and heuristic }\end{array}$ & $\begin{array}{c}\text { Stochastic } \\
\text { mathematical } \\
\text { programming }\end{array}$ \\
\hline Visintin et al. (2016) & $\sqrt{ }$ & $\sqrt{ }$ & $\sqrt{ }$ & & & & $\begin{array}{l}\text { Hybrid simulation } \\
\text { and mixed } \\
\text { integer programming }\end{array}$ & $\begin{array}{c}\text { Mixed } \\
\text { integer } \\
\text { programming }\end{array}$ \\
\hline Riise et al. (2016) & $\sqrt{ }$ & & $\sqrt{ }$ & & & & Heuristic & $\begin{array}{l}\text { A multi-project, } \\
\text { multi-mode } \\
\text { resource-constrained } \\
\text { project-scheduling } \\
\text { problem }\end{array}$ \\
\hline Riise et al. (2012) & $\sqrt{ }$ & & $\sqrt{ }$ & & & & $\begin{array}{l}\text { Mixed integer } \\
\text { programming }\end{array}$ & $\begin{array}{l}\text { A multi-project, } \\
\text { multi-mode } \\
\text { resource-constrained } \\
\text { project-scheduling } \\
\text { problem }\end{array}$ \\
\hline Our paper & $\sqrt{ }$ & $\sqrt{ }$ & & & $\sqrt{ }$ & & $\begin{array}{l}\text { Hybrid simulation } \\
\text { and heuristic }\end{array}$ & $\begin{array}{l}\text { A multi-project, } \\
\text { multi-mode resource- } \\
\text { constrained project- } \\
\text { scheduling } \\
\text { problem }\end{array}$ \\
\hline
\end{tabular}

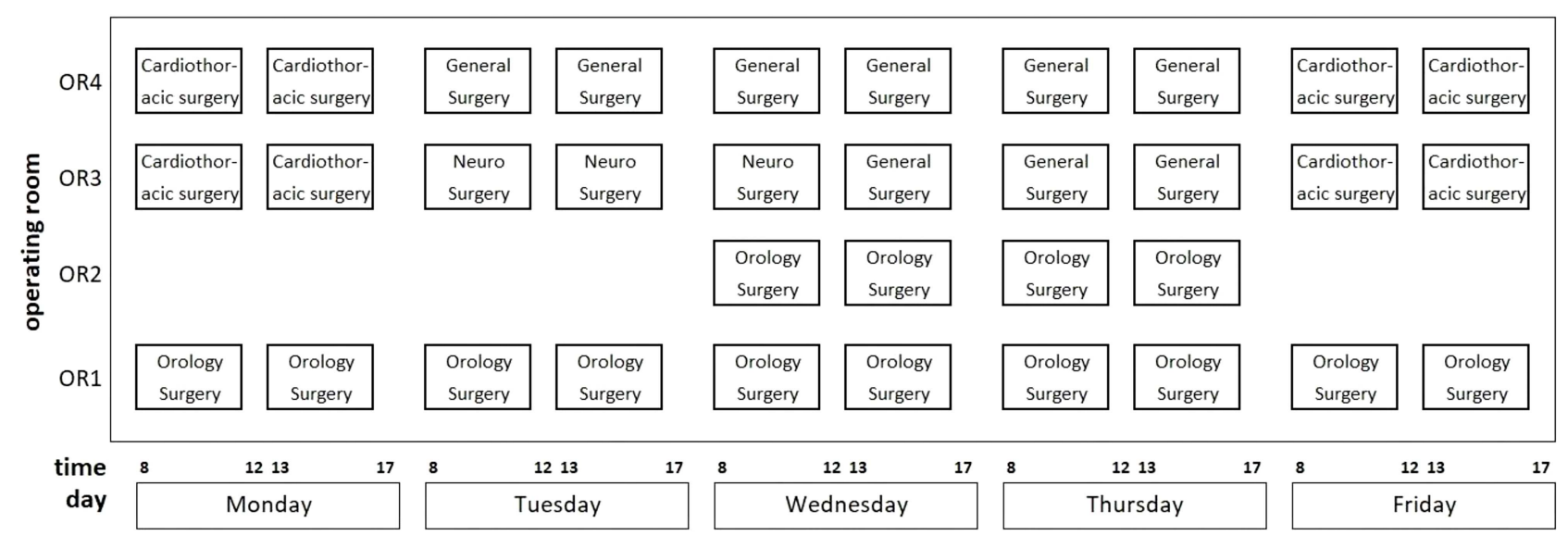

Figure 2. An instance of OR time blocks.

the execution of $N^{p}$ treatment activities, e.g., preparing the patient, preparing the OR, surgery, cleaning the OR, and recovery. Various precedence relations (including the maximum and minimum time lags) can be assumed between each pair of these activities in any patient's surgery. As an instance, maximum time lag can explain the extreme waiting time of a patient between a pair of activities. Usually, more than one set of resources or activity modes can be applied for the execution of activities. As discussed in the previous section, activity modes in surgery activity resulted from various combinations of different surgeons with the same specialty and different ORs. Each activity mode has its own set of resources and durations.

In any activity $i$ in any patient's surgery $p \in P$, there is a set of activity modes $M^{i}$. The selection of one of the activity modes $m \in M^{i}$ is necessary for the execution of this activity. This selection clarifies a set of resources $R^{m}$ where the number of $\mu_{r}^{m}$ units of any resources $r \in R^{m}$ is necessary for the execution of the activity. The simultaneous availability of all the resources in the activity mode is necessary for the execution of the activity.

Each patient surgery is considered as a project. 
The execution of this project means scheduling all of its activities. Keeping the project activities unscheduled makes scheduling other activities useless; thus, these activities must be removed from the schedule.

\subsection{Inter-activity mode compatibility constraints and project modes}

Some resources (such as OR and surgeon) are applied in more than one activity in a project. It is necessary to use the same resource in the case of all the activities in a project. For instance, if two activities in a project require resource $\mathrm{OR}$, the same OR must be used in this project. Inter-activity mode compatibility constraints represent a group of constraints that guarantee the usage of the same common resource among the activities of a project. Project modes are a set of various combinations of common resources in a project and are utilized for implementing these constraints. Inter-activity mode compatibility constraints limit the selection of activity modes to those modes, which are compatible with a project mode.

As an illustration, consider a sample project $p_{1}$ that consists of two activities $P=\{$ Surgery, Cleaning $\}$. Activity Surgery is the predecessor of activity Cleaning with precedence relation $F S^{\max }$ (15) (activity Cleaning must start up to 15 minutes after the termination of the activity Surgery). The execution of Surgery activity requires one Surgeon and one $O R$, and also the execution of Cleaning activity requires one $O R$ and one Cleaner. It is supposed that resource type OR contains three resources $\left(O R_{1}, O R_{2}, O R_{3}\right)$. The inter-activity mode compatibility constraint states that when resource $O R_{1}$ is used for activity Surgery in the project $p_{1}$, only $O R_{1}$ must be used for the activity Cleaning in this project. Project mode only contains the OR resource type here and gets one of $\left\{O R_{1}\right\}$, $\left\{O R_{2}\right\}$, and $\left\{O R_{3}\right\}$, among which $\left\{O R_{1}\right\}$ is selected as the project mode.

Generally, to implement inter-activity mode compatibility constraints in any project $p \in P$, some project modes $W^{p}$ are considered. The selection of a project mode $w \in W^{p}$ in any project $p \in P$ leads to the fact that in any activity $i \in N^{p}$, only a subset of activity modes $M_{w}^{i} \subset M$ remains compatible with the selected project mode. Each activity mode $m \in$ $M^{i}$ has its activity duration which is dependent on some resource considerations such as surgeon's skills or whether the surgery is performed in the training mode or not.

\subsection{Project's disjunction constraints}

The project's disjunction constraints prevent the use of a common resource in other projects at the interval between its first usage in a project and the completion of its last usage in the same project. It means that these constraints make a common resource quarantined and unavailable after its first usage in a project, similar to other projects. A resource can be available for other projects only after the termination of its last usage in the activities of the current project. For the sake of more clarity on the project's disjunction constraint, suppose another project $p_{2}$ with the same structure as $p_{1}$ discussed previously. Suppose the project $p_{1}$ is before the project $p_{2}$ in the schedule. Now, in both of them, the project mode $\left\{O R_{1}\right\}$ is selected (both of the projects require the usage of the same common resource). The project's disjunction constraint states that the activity Surgery in the project $p_{2}$ cannot start until the activity Cleaning of the project $p_{1}$ is terminated, even if the resource $O R_{1}$ remains idle between the activities Surgery and Cleaning of the project $p_{1}$.

This problem is classified as a multi-project, multi-mode resource-constrained project-scheduling problem with generalized precedence in the literature and this belongs to NP-hard problems [25,31]. The mathematical model of this problem in the case of scheduling elective surgeries was presented as a mixedinteger linear programming model by Riise and Mannino [31]. Then, we extended that mathematical model by considering both elective and emergency surgeries when the BIMs approach in the flexible OR policy was implemented [32]. For scheduling elective surgeries in real-size problems, Riise et al. presented the GOSSP algorithm [25].

This study develops an algorithm called Scheduling Elective and Emergency Surgeries (SEES). As mentioned in the introduction, scheduling emergency surgeries and the efficient usage of ORs are challenges for hospital managers. The BIMs approach was applied to the flexible OR policy and its efficiency in emergency surgery scheduling was examined. A Norwegian medium-sized hospital data available on the web for testing our algorithm were utilized [33]. The BIMs approach enjoys the capability of scheduling emergency surgeries with efficient use of ORs capacities. Moreover, this approach has received less spotlight in the literature. To the best of our knowledge, this approach has not been implemented before in an environment where surgeries are considered as projects. In this method, any emergency surgery is inserted into the schedule after terminating one of the currently undergoing surgeries or, in other words, at the BIMs. For minimizing the waiting time in emergency surgeries, it is necessary to minimize the interval between the sequential BIMs in the sequencing of elective surgeries. This problem entails minimizing the maximum interval between sequential BIMs [14].

As discussed earlier, our main contribution is to implement the BIM approach when each surgery is a project with multi-mode activities. The most important requirement for implementing the BIMs 
approach is to know the duration of OR usage in the projects. Although we only consider the problem in a deterministic state, we cannot estimate the duration time of surgery activities with distinct values. The first reason is that in the surgery activity of a project, the durations in different ORs are not the same because of the difference between activity modes. The second reason is that variation in the durations in the activity surgery in a project is not negligible because of the large number of activity modes (in some projects, there are 36 activity modes for activity surgery). As discussed before, the main cause of this variation in durations lies in some resource considerations. For instance, the surgeon's experience or whether the operation is in the training environment or not can change the duration of the surgery activity.

The GOSSP algorithm belongs to a class of NPhard optimization problems [25]. Moreover, OR planning with elective and emergency surgeries is a strongly NP-hard problem [34]. Furthermore, adjusting the BIMs is a strongly NP-hard problem, in which case the number of ORs exceeds one [14]. Due to the difficulty of solving this problem, we extend the original meta-heuristic algorithm of the GOSSP conveniently to handle emergency surgeries at the BIMs. The next section presents the SEES algorithm.

\section{Proposed algorithm}

The SEES algorithm concerns scheduling elective and emergency patient's surgeries. This algorithm initially provides a schedule of elective surgeries. Then, during the execution of this schedule, after the arrival of any emergency surgery, it attempts to insert the emergency surgery into the schedule with rescheduling.

\subsection{Constraints}

Some constraints are the same in both of the problems of scheduling and rescheduling of elective and emergency surgeries. Scheduling a project requires satisfying all the constraints mentioned in the previous section (such as availability of resources, precedence relations between activities, inter-activity mode constraints, and project's disjunction constraints). However, it is necessary to consider some factors during the scheduling of elective surgeries to implement the BIMs. This study develops a new heuristic for scheduling elective surgeries. Inserting elective surgeries to a partial schedule is bound to potential insertion of a possible coming emergency surgery up to a limited period to the schedule. Each elective surgery can be inserted into the schedule only after satisfying one of the following conditions. First, after the estimated start time in an elective surgery up to a limited period (maximum tolerable waiting time in the emergency surgeries), one of the ORs becomes free and remains available for a specific duration (the average duration of emergency surgeries). Second, after the estimated start time of the elective surgery up to a limited period (the maximum tolerable waiting time in the emergency surgeries), another elective surgery starts in one of the ORs. The possible coming emergency surgery can access an OR in a tolerable waiting time, because in the first case, one of the ORs becomes free while in the second case, the emergency surgery is substituted instead of one of the elective surgeries in the schedule. However, these limitations do not apply to emergency surgeries. Providing their resources is the only condition for inserting emergency surgeries to schedule.

\subsection{Objective components}

Usually, scheduling all the projects is impossible. A feasible schedule results from scheduling activities of a subset of total projects $\tilde{P} \subset P$. Selecting this subset depends on some objective components. For scheduling these selected projects $(\tilde{P})$, it is necessary to select an activity mode $m \in M_{w}^{i}$ and a feasible start time for any activity $i \in N^{p}$ in each project $p \in \tilde{P}$. The selection of an activity mode $m$ and determination of start time for each activity $i$ should be compatible with the availability of all of the resources $r \in R^{m}$ in the activity mode $m$. Moreover, for scheduling the projects, all the previously mentioned constraints should be satisfied.

Various objective components are included in the SEES through a linear combination and it is supposed that minimization of the objective function is desirable. If we consider $O$ as the objective function, then $O^{f}$ is an objective component and $\alpha_{f}$ is its corresponding weight. The next formula illustrates the SEES objective function:

$$
O=\sum_{f} \alpha_{f} O^{f}
$$

As will be discussed in the following, each of the objective components has a specific scale; a simple summation of the weighted objective components is not reasonable. Therefore, each of the objective components is normalized. The variable $O^{f}$ refers to the normalized objective component. In this way, the effect of different scales is removed from the objective function.

In this problem, we consider many objective components. Some of them ('unscheduled surgeries', 'patient's waiting time', 'violation of scheduling children and patients with diabetes in the early day', and finally 'makespan' or finishing the schedule early in the day) come from the GOSSP. Moreover, we include some other objective components in the SEES as in the following.

The deviance for the start times of the elective surgeries between the final schedule (after inserting all emergency surgeries) and the initial schedule (that 
only includes elective surgeries) is calculated in the 'un-stability' objective component. This objective component is the summation of the violation of start times of elective surgeries in the final schedule from their start times in the initial schedule.

The problem includes various ORs, each of which has its OR capacity, and the ' $V O R L$ ' objective component tends to resource leveling through balancing the OR usage. The value of this objective component is equal to the difference between the maximum and minimum percentages of OR usage among various ORs in the schedule. For instance, suppose a case in which there are three ORs; in the final schedule, $85 \%$ of the total available capacity of $O R_{1}, 25 \%$ of the total available capacity of $O R_{2}$, and $70 \%$ of the total available capacity of $O R_{3}$ are consumed. In this case, the ' $V O R L$ ' takes the value of 60 , which is the difference between 85 and 25 .

Any patient surgery has its due date and it is desirable to start without any lateness to achieve its due date. Therefore, we consider the following objective components: 'the number of electives scheduled with lateness' ('NElecL'), 'the number of emergencies that scheduled with lateness' ('NEmgL'), 'the summation of lateness in electives' ('SLElec'), and 'the summation of lateness in emergencies' ('SLEmg').

We also consider some special objective components that are related to elective surgeries: 'the number of unscheduled electives' ('NUnElec') and 'average waiting time in electives' ('AWTElec'). Similarly, for emergency surgeries, the following objective components are added: 'the number of unscheduled emergencies' ('NUnEmg') and 'average waiting time in emergencies' ('AWTEmg'). In this paper, it is supposed that the entire patient surgeries should be scheduled at ordinary working hours. Only those emergency surgeries that remain unscheduled during ordinary working hours can be scheduled in overtime.

\subsection{ACI function}

The SEES algorithm is a constructive-improvement algorithm and consists of some functions. The main function of the SEES algorithm is ACI function or adaptive construction and improvement algorithm, which is an iterative search algorithm. The $A C I$ function (Figure 3) uses a limited size pool for maintenance of schedules and the corresponding Project Insertion Order (PIO). Each schedule has a PIO that keeps the order of insertion of each project into this schedule. For example, if we suppose the set of projects as $P=$ $\left\{\right.$ Project $_{1}$, Project $_{2}$, Project $\left._{3}\right\}$, then the array PIO $=$ $(2,3,1)$ means that the first project for scheduling is Project $_{2}$ followed by Project 3 and Project P. This $_{3}$ function always updates the best schedule of the pool after any change in each iteration of the execution. At each iteration, a decision determines whether a new schedule should be constructed or one of the pool's schedules must be improved. A roulette wheel sampling makes this decision. This roulette wheel works based on how much each of the two methods (construction of a new schedule or improvement of one of the existing schedules) has been successful in reaching a good solution.

The construction method creates a new schedule. Each project has a clinical priority that exhibits its importance for early scheduling. A roulette wheel sampling, which works based on these projects' priorities, is applied to generate a PIO $\pi^{\prime}$. Then, the Schedule Creator function that will be discussed later in this section uses the PIO $\pi^{\prime}$ and a parameter to create a schedule.

This parameter has a critical role in mode selection (activity modes and project modes) in the process of inserting projects into the schedule.

For scheduling each project, different project modes and different activity modes lead to the usage of different sets of resources and result in different duration times. Three parameters for scheduling a project are considered: 'the best objective function', 'the earliest finish time', and 'the first feasible mode'. Another roulette wheel sampling is applied to selecting the parameter, which works based on each parameter's success to conduct good schedules. The Schedule Creator function finally generates the schedule $S^{\prime}$ and adds this schedule $S^{\prime}$ and its corresponding PIO $\pi^{\prime}$ to the pool.

The improvement method improves one of the existing schedules of the pool and the selection is done randomly, but better schedules have a higher chance of selection. The Insertion Order Modification function tries to modify the PIO, $\pi$ of the selected schedule $S$ and gives the resulting $\mathrm{PIO}, \pi^{\prime}$.

If the new PIO, $\pi^{\prime}$ remains the same as the previous $\pi$, then the algorithm tries to select another schedule from the pool. This step is repeated until the modified PIO differs from its initial PIO. Then, the Schedule Creator function is employed to generate a new schedule, $S^{\prime}$, through the modified PIO, $\pi^{\prime}$. Finally, the resulting schedule, $S^{\prime}$, with its PIO, $\pi^{\prime}$ is replaced by $S$ and $\pi$ in the pool.

After any change in the pool, the best schedule of the pool is updated. Then, the success of construction and improvement methods and the success of various parameters in reaching good solutions are updated in their learning mechanisms separately. Finally, after completing its execution, the $A C I$ function returns the best schedule of the pool as its output.

In the SEES algorithm, initially, the $A C I$ function is executed for producing a schedule for elective surgeries or equivalently elective projects. That is offline scheduling, and the resulting schedule is valid before the arrival of the first emergency surgery. After the 


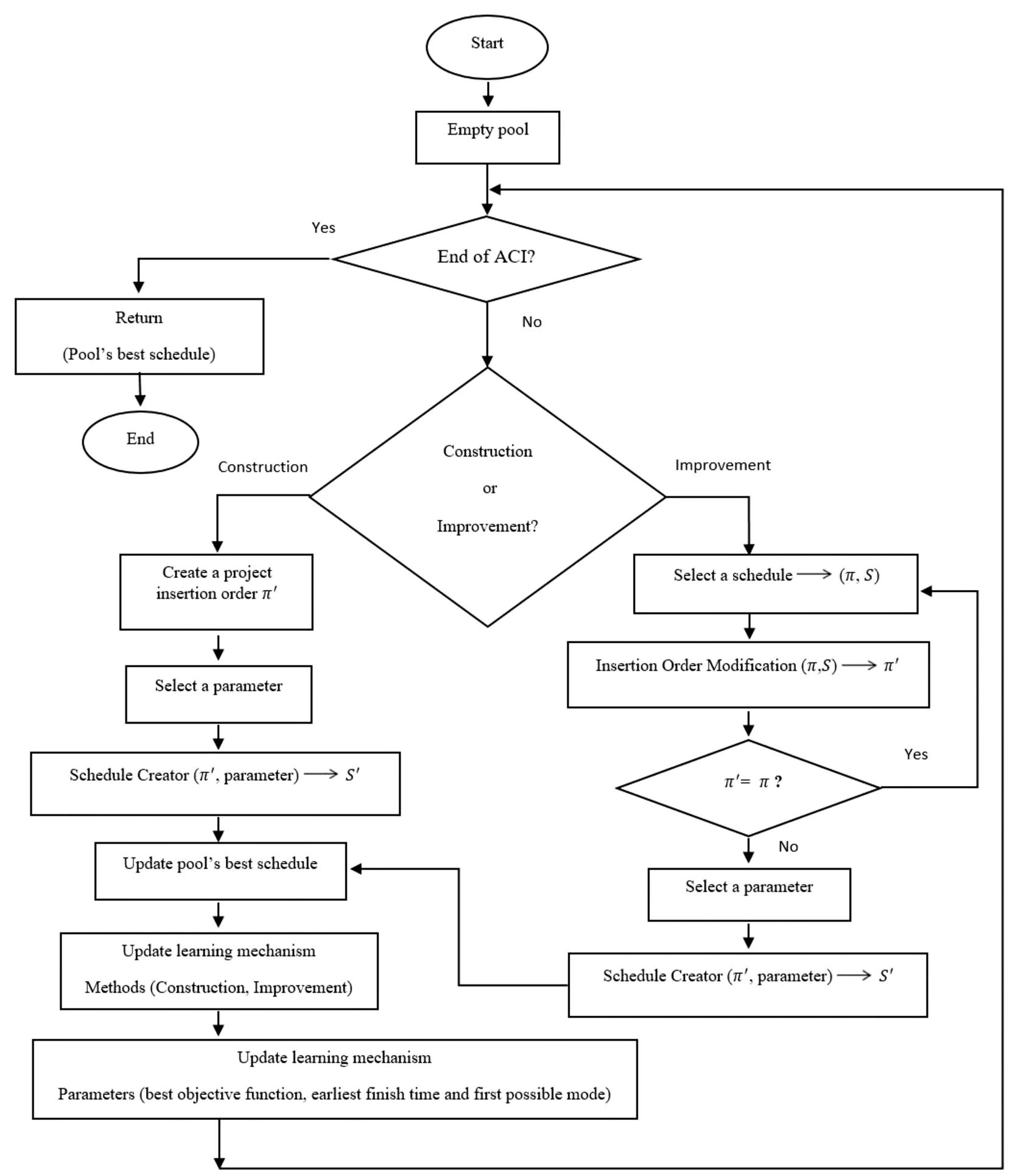

Figure 3. Adaptive construction and improvement algorithm (ACI function).

arrival of any emergency surgery, old projects take one of these three various states. The execution of some projects is terminated before this arrival time and some of them are currently undergoing surgeries, but they are not complete and the last ones are those that have not been initiated yet.

The SSP is non-preemptive scheduling. There- fore, insertion of the emergency surgery to the schedule takes place right after the currently undergoing surgeries are finished and prior to the projects that have not been started yet. Moreover, after the arrival of any emergency surgery, the state of resources must also be updated and modified to consider the consumed and inuse capacities. After these changes, the $A C I$ function 
is employed again for producing a new schedule. This process is repeated after any emergency arrival, and it creates online schedules.

\subsection{Schedule Creator function}

In $A C I$ function, if the construction method is selected, then Schedule Creator function creates a new schedule from a new PIO and a parameter. Figure 4 illustrates the algorithm of Schedule Creator function. This function partially schedules the projects one by one, according to the PIO. Initially, a random activity order $\pi^{p}$ is generated for the set of activities $N^{p}$ in any project $p \in \pi$. In this activity order, all the precedence relations between activities are considered.

For initialization, the variable $w^{*}$ is set to null and this variable refers to the selected project mode, and the set feasiblews is cleared, this set collects all the feasible project modes. The variable $\operatorname{Pr} o$ Param is initialized to the input parameter. This variable indicates the selected parameter for scheduling a project. It is only in case of emergency surgeries that the value of this variable changes to 'the earliest finish time' in order to consider the urgency of these surgeries.

Next, the algorithm searches among various project modes $w \in W^{p}$ to find the best project mode for scheduling the project $p$. For each project mode, the $S G S\left(S, p, w, \pi^{p}, \operatorname{Pr}\right.$ o Param) function tries to insert activities of the project $p$ with the activity order $\pi^{p}$ and project mode $w$ into the partial schedule $S$ with the parameter $\operatorname{Pr}$ o Param. This function is the most complicated part of the Schedule Creator function because this function should satisfy all the constraints mentioned in the previous section during the insertion of the activities to the partial schedule. If the $S G S$ function can schedule the project $p$, then it is investigated whether the project is an emergency surgery or not. The success of the $S G S$ function is sufficient in the emergency surgeries, but the following conditions must be examined in elective surgeries for encountering probable coming emergency surgeries.

From the start time of using the OR in the elective surgery $p$ until a specified time later ('the Predefined BIM Interval' (PBIMI)), another BIM must be found, or one of the ORs must be available. Moreover, the available OR must remain accessible for a specific duration ('the Mean Surgery Time for emergency surgeries' (MST)). If the project mode $w$ overcomes these conditions, then the project mode will be inserted into a group of feasible project modes.

Then, this project is removed from the partial schedule and this process is repeated to examine the feasibility of other project modes. Finally, the best project mode is chosen for inserting the project into the schedule. This process is repeated for all projects in PIO. At the end of the algorithm, the Schedule Creator function returns the resulting schedule as its output.
Figure 5 gives more explanation on the feasibility conditions of project modes in elective surgeries. For inserting Surgery $_{1}$ into the schedule, $O R_{2}$ is available at the $B I M_{2}$. Since the distance between $B I M_{1}$ and $B I M_{2}$ is less than 'PBIMI' and $O R_{2}$ is available for an interval as long as ' $M S T$ ', this project is inserted into the schedule. In the second case, Sergery $y_{2}$ can be inserted into the schedule, because $O R_{1}$ is available for an interval longer than ' $M S T$ '. However, in the case of inserting Surgery $_{3}$ to the schedule, none of these conditions is satisfied because none of the ORs becomes free during the interval of ' $P B I M I$ ' and none of the elective surgeries starts in this interval. Therefore, this project cannot be inserted into the schedule.

\subsection{Insertion Order Modification function}

The $A C I$ function is based on the selection of one of the construction and improvement methods. In the improvement method, a roulette wheel selects a schedule and its corresponding PIO from the pool for improvement. The main idea for improving a schedule is that earlier projects in PIO have a higher chance to be scheduled better than the other projects.

Therefore, after recognizing the projects with more contributions to the objective function, the Insertion Order Modification function tries to move their position earlier in the PIO. The Insertion Order Modification function uses the vector $\pi E P$ that keeps the earliest position in which each project has ever been in the schedule. Then, this function recognizes a set of projects with more contributions to the objective function or bad projects. These projects are sorted based on their earliest positions in $\pi E P$ and their contributions to the objective function. After that, the Insertion Order Modification function tries to take their positions to one place earlier than their positions in $\pi E P$. In case that two projects compete for one place, one of these projects is randomly selected for that position while the other one takes place in the next position. Finally, this function returns the new PIO to the $A C I$ function. Figure 6 illustrates the Insertion Order Modification function.

\section{Computational results}

\subsection{Data specifications}

We use real information of the patients in a Norwegian hospital, which is available on the web [33], for testing our algorithm. The file w40-1 is selected as the data source of elective surgeries. This file contains the availability information of resources and the details of 40 patients' surgeries, including their activities, project modes, and activity modes. Then, file w40-2 is used as the data source for emergency surgeries so that it can incorporate the information of the other 40 patients' surgeries. Except for disaster conditions, usually, 


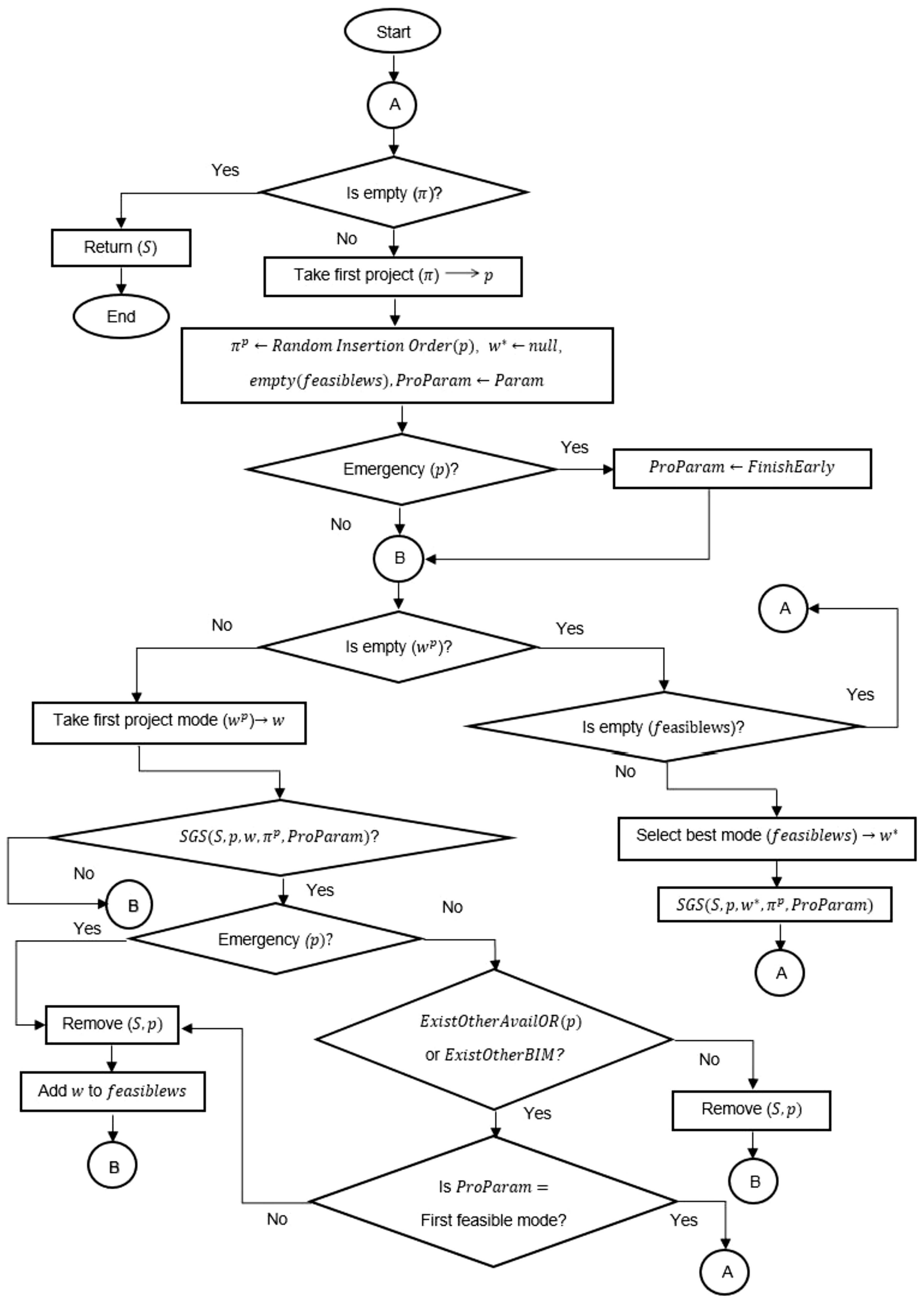

Figure 4. Schedule Creator Function. 


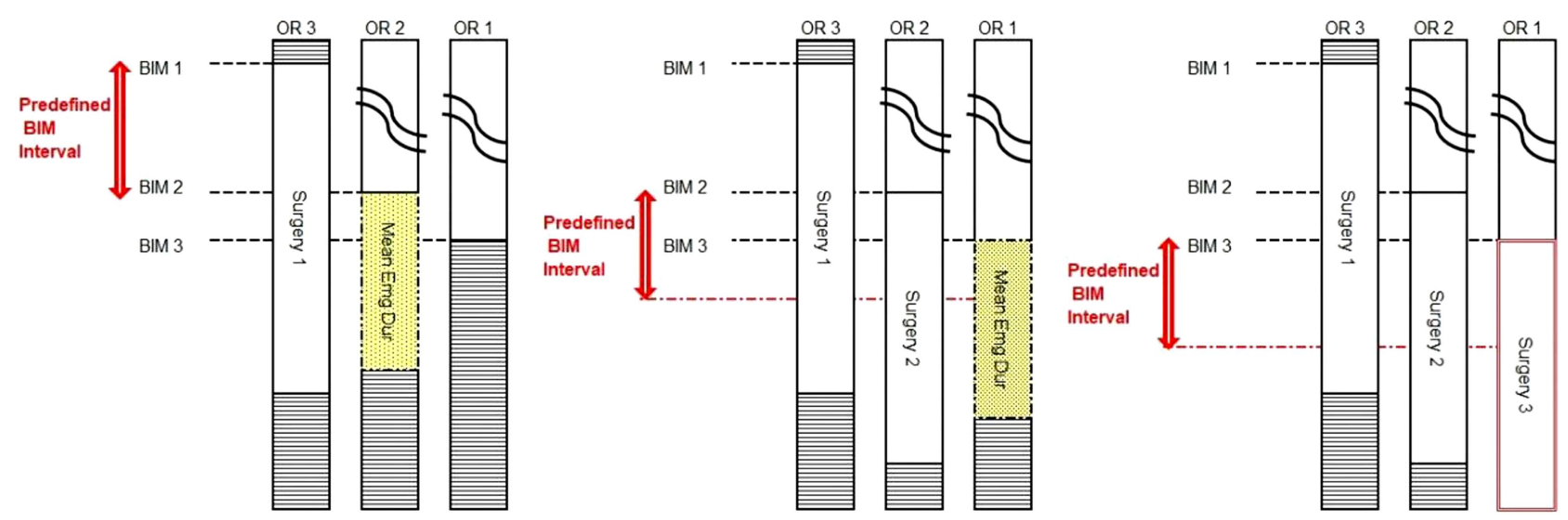

Figure 5. Scheduling of elective surgeries with respect to adjusting the BIMs.

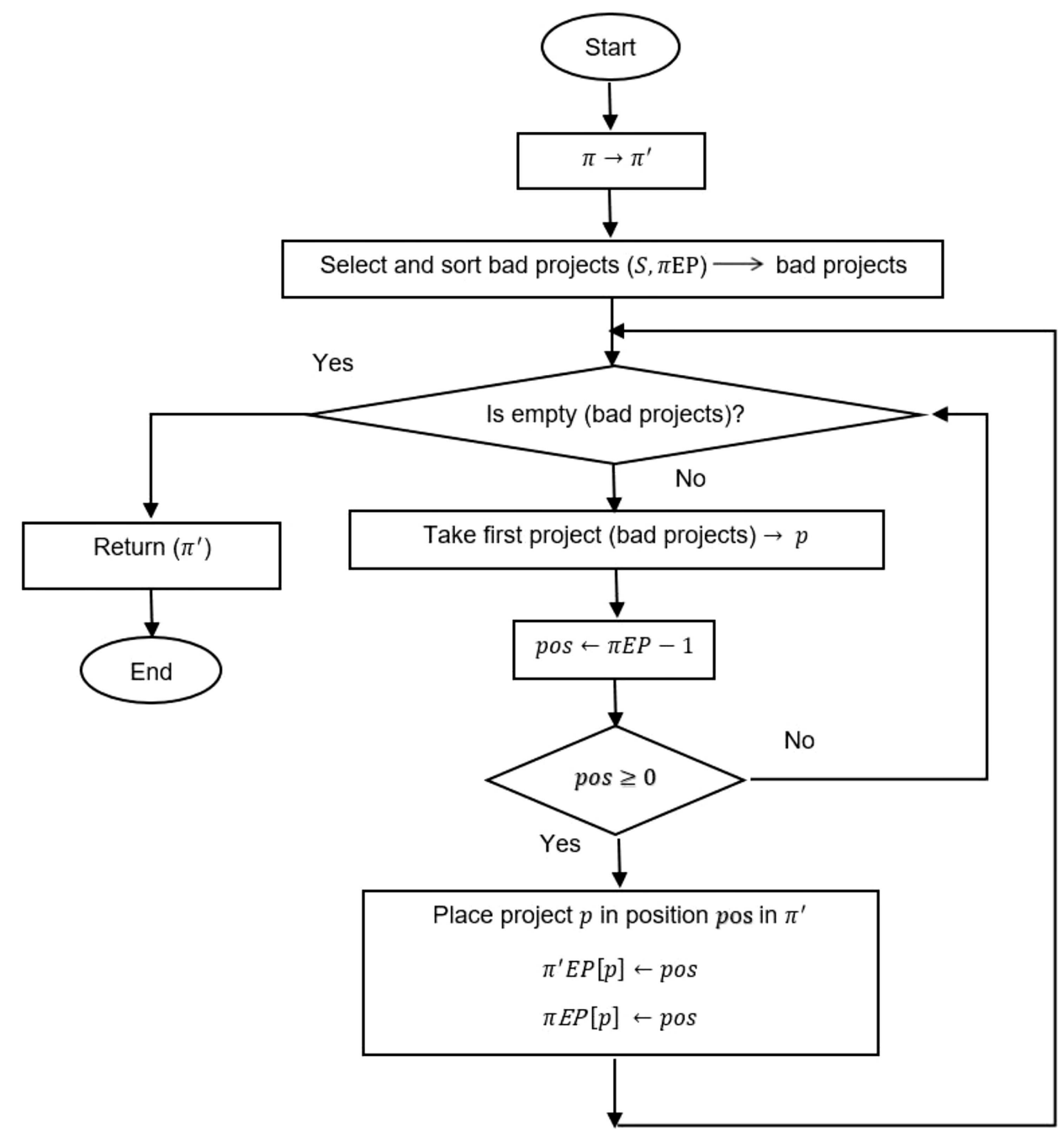

Figure 6. Insertion Order Modification function.

the number of emergency surgeries is supposed as a specific percentage of the number of elective surgeries. Bowers and Mould found that the number of emergency patients is about $25 \%$ of the number of elective patients at the orthopedic department [35]. In this study, the number of emergency surgeries is supposed $20 \%$ of the number of elective surgeries; therefore, in each experiment, eight projects are selected randomly from file w40-2 as emergency surgeries.

\subsection{Projects' specifications}

In our problem instance, each project consists of 
three activities: surgery, recovery, and cleaning $p=$ $\{$ Surgery, Recovery, Cleaning $\}$. The surgery activity is the predecessor of the other two, and both of the recovery and cleaning activities can start simultaneously. Execution of activities in any project requires a subset of four resource types including ORs, surgeons, recovery rooms, and cleaners $R=$ $\{$ ORs, Surgeons, Recovery Rooms, Cleaners $\}$. Resources are available at some capacities in some availability intervals. Because of the existence of OR time blocks, the OR resource in each availability interval is only usable by surgeries from a specific surgery specialty (such as urology). It is supposed that emergency surgeries can be performed in any available OR with no respect for OR time blocks. The period of scheduling is one week, and all the elective surgeries that cannot be scheduled in a week remain unscheduled. Only emergency surgeries that remain unscheduled will be scheduled in overtime.

\subsection{Comparison of methods}

To investigate the efficiency of our proposed algorithm in dealing with emergency surgeries, two different methods are considered. In the first one, elective surgeries are scheduled regardless of adjusting the consecutive BIMs interval (ordinary scheduling). In the second one, scheduling elective surgeries is tied up to adjusting the BIMs as discussed in Schedule Creator function (scheduling surgeries with the BIMs interval adjustment).

In the first method (ordinary scheduling), the only condition for the acceptance of a project mode in the Schedule Creator function is the success of the $S G S$ function in inserting the patient's surgery with this project mode into the schedule.

In the BIMs interval adjustment method (the second method), besides the above-mentioned conditions for scheduling elective surgeries, the existence of another BIM or available OR is examined.

In both methods, after the arrival of emergency surgery, the PIO changes in a way that the emergency surgery is inserted before all the projects that have not be initiated yet. Then, online rescheduling with this new PIO is done. Both methods are implemented in the Visual $\mathrm{C}++$ environment and run under Windows 8.1 on a system featuring Intel Core i7, $2.2 \mathrm{GHz}$ processor, and 8 GB RAM.

\subsection{Quality measurements and main factors}

This study investigates whether (a) the BIMs interval adjustment has any role in decreasing the waiting time for emergency surgeries and (b) how this method influences other quality measurements. Initially, some factors that can affect the waiting time for emergency surgeries are recognized as follows: 'the way of scheduling', 'emergency arrival times', and 'emergency
Table 2. Priorities of emergency surgeries.

\begin{tabular}{lcccc}
\hline Due-date (min) & 60 & 120 & 180 & 240 \\
Probability & 0.25 & 0.25 & 0.25 & 0.25 \\
\hline
\end{tabular}

surgeries priorities' (or their due dates for the operation). Moreover, in the second method of scheduling that adjusts the BIMs interval, two parameters 'MST' and 'PBIMI' can affect the scheduling of emergency surgeries. To deal with these variability factors in our experiments, 'emergency arrival times' and 'emergency projects priorities' are randomized, and different levels are considered for 'MST' and 'PBIMI' parameters.

A Poisson process for modeling the emergency arrival process is utilized. Given that the weekly period consists of several workdays, 'emergency arrival times' are adjusted such that they can occur only during work hours. In the case of 'emergency projects priorities' or project's due dates, it is supposed that the due date of each emergency surgery randomly takes one of the numbers $60,120,180$, or 240 minutes with an equal probability (Table 2).

For choosing the levels of 'MST' and 'PBIMI' factors, we suppose that the first method is equivalent to the second method when 'MST' is zero and 'PBIMI' is 15000 , being longer than the scheduling period. In the second method, two levels of 100 and 300 minutes for the factor 'MST' and two levels of 60 and 90 minutes for the factor 'PBIMI' are chosen based on our data. Thus, the required experiments can be classified at different levels of two main factors. Table 3 shows the details.

We consider seven different patterns of emergency surgeries with the following discussion. These patterns are implemented by selecting eight projects randomly as emergency projects, eight arrival times from the Poisson process that are adjusted in the weekly working hours for emergency arrivals, and eight surgery priorities that are selected randomly based on Table 2 for the due dates of emergency surgeries.

Finally, our elective surgeries are scheduled based on various settings of two main factors and their levels are mentioned in Table 3. In each schedule, all the seven patterns of emergency surgeries are examined and the values of the response variables are collected. This step is repeated ten times. Table 4 shows the average of the response variables in each pattern. Table 5 refers to the mean of response variables at different levels of two main factors.

Then, these results are analyzed by Factorial ANOVA analysis in SAS software at the confidence level $(\alpha=0.05)$. This analysis tests whether the mean of quality measurements is the same at varying impact levels. Factorial ANOVA cannot indicate what impact levels cause a difference in the mean of the response variable. Therefore, Tukey's Studentized Range (HSD) 
Table 3. Main factors and their levels.

\begin{tabular}{cccc}
\hline & Factor A & Factor B & Description \\
\cline { 2 - 3 } & PBIMI & MST & \\
\hline \multirow{3}{*}{ Levels of factors } & 15000 & 0 & Ordinary scheduling method \\
\cline { 2 - 3 } & 60 & 100 & \\
\cline { 2 - 3 } & & 300 & \multirow{2}{*}{ The BIMs interval adjustment method } \\
& 90 & 300 & \\
\hline
\end{tabular}

test, which is one of the most common ANOVA Posthoc tests, is used after the Factorial ANOVA analysis at the same confidence level.

This section investigates whether changing the impact levels of 'MST' and 'PBIMI', as well as their interaction effect, is statistically significant in the mean of the response variables. The Factorial ANOVA tables summarize the information about the sources of variation in our quality measurements. The results of Factorial ANOVA for response variables related to emergency surgeries are presented in Tables 6 to 9 . The p-values in Tables 6,7 , and 8 do not identify any statistically significant factor. On the other hand, the p-value for the main effect of 'PBIMI' in Table 9 is less than the significant level $(\alpha=0.05)$. In this way, this effect is statistically significant and we can reject the null hypothesis concerning the equality of the means of response variable 'AWTEmg'. Tukey test is conducted to distinguish the mean of the response variable in which levels of 'PBIMI' vary from one another. Table 10 shows the comparison of the means of 'AWTEmg' between levels 90 and 15000 of 'PBIMI' and levels 60 and 15000 of 'PBIMI', which are statistically significant at a level of 0.05 ; however, this comparison is not statistically significant at levels 60 and 90 of 'PBIMI'. Thus, according to Tables 10 and 5 , we can conclude that the mean of 'AWTEmg' at levels 60 and 90 of 'PBIMI' are smaller than level 15000 of 'PBIMI'.

In other words, we can summarize all of the above analyses about the quality measurements related to emergency surgeries as follows: The BIMs interval adjustment has a better performance in 'AWTEmg', but there is no evidence to suggest that each of these methods has a better performance in terms of ' $N E m g L$ ', ' $N U n E m g$ ', and 'SLEmg'.

The results of Factorial ANOVA for response variables related to elective surgeries are presented in Tables 11 to 14 . In the case of quality measurements related to elective surgeries, similarly, the following results are obtained. The p-value column in Table 11 that is related to 'NElecL' does not indicate any statistically significant factor. However, this column in Table 12 indicates that the factors 'PBIMI', 'MST', and their interaction are statistically significant for 'SLElec'. Since the interaction of the effects is present, our main effects do not have their usual interpretations. It is difficult to state how independent effects of 'PBIMI' and 'MST' act because the nature and magnitude of each effect depend on the particular level of another effect. In the case of 'NUnElec', Table 13 shows that the effect of 'MST' is statistically significant. The Tukey test results (Table 15.) show that all the levels of 'MST' are statistically significant. Tables 5 and 15 show that the mean of 'NUnElec' has its lowest value when 'MST' is at level 0 , while 'NUnElec' has its highest value when 'MST' is at level 300 .

Investigating the p-value column in Factorial ANOVA for 'AWTElec' (Table 14) shows that both of the main effects of 'PBIMI' and 'MST' are statistically significant. The results of the Tukey test in Table 16 verify that the difference between the means at levels 60 and 15000 of 'PBIMI' and levels 60 and 90 of 'PBIMI' is statistically significant. Tables 16 and 5 indicate that the mean of 'AWTElec' gets its highest value at level 60 of the 'PBIMI'. However, the results of the Tukey test (Table 17) do not detect which 'MST' levels can cause a meaningful difference between 'AWTElec' values.

Tables 18 and 19 are related to 'Un-stability' and 'VORL'. ANOVA Factorial analysis of 'Un-stability' in Table 18 shows that the 'PBIMI' effect is meaningful, and its related Tukey test analysis in Table 20 indicates that the difference between the means at levels 60 and 15000 of 'PBIMI' is statistically significant. Tables 21 and 5 show the mean of 'Un-stability' when 'PBIMI' at level 60 gets a higher value than the case where 'PBIMI' is at level 15000. However, ANOVA Factorial analysis of ' $V O R L$ ' in Table 19 does not indicate any statistically significant factor.

Finally, Table 21 shows the results of Factorial Analysis for 'Objective Function'. In this table, the p-value column indicates that 'PBIMI' is statistically significant. Tukey test in Table 22 indicates that the comparison between the means at levels 90 and 15000 and levels 90 and 60 is statistically significant. Investigation of Tables 22 and 5 verifies that the 'Objective Function' gets its lowest value when 'PBIMI' is at a level of 90 . 
Table 4 . The average of response variables after 10 repeats.

\begin{tabular}{|c|c|c|c|c|c|c|c|c|c|c|c|c|c|}
\hline$\dot{0}$ & $\sum_{B_{1}}$ & $\stackrel{N}{E}_{E^{2}}^{N}$ & 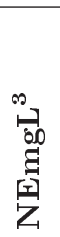 & 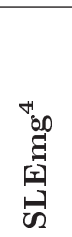 & 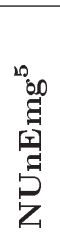 & ${ }_{3}^{0}$ & 氞 & 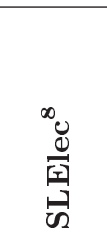 & 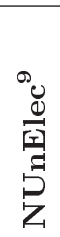 & 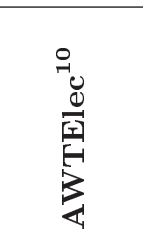 & 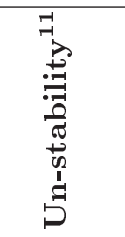 & 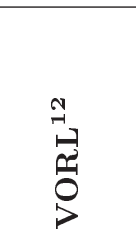 & 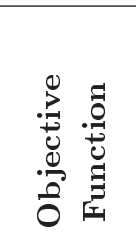 \\
\hline \multirow{5}{*}{1} & 15000 & 0 & 0.2 & 31 & 1.7 & 54.45189 & 1 & 1021.1 & 0.4 & 2964.011 & 19674.3 & 11.396 & $1.96 \mathrm{E}-04$ \\
\hline & 60 & 100 & 0.6 & 13.9 & 1.8 & 26.5106 & 0.4 & 2965 & 1.8 & 3330.926 & 20027.9 & 12.422 & $2.34 \mathrm{E}-04$ \\
\hline & 60 & 300 & 0.4 & 23.1 & 1.4 & 37.5964 & 0.5 & 1982.5 & 7.1 & 3211.499 & 26210.9 & 10.6417 & $3.07 \mathrm{E}-04$ \\
\hline & 90 & 100 & 1 & 10.9 & 1.9 & 42.1469 & 0.5 & 4986.4 & 1 & 3024.604 & 13620.6 & 11.4084 & $2.29 \mathrm{E}-05$ \\
\hline & 90 & 300 & 0.3 & 25.7 & 1.6 & 44.2418 & 0.7 & 1497.1 & 7.1 & 2950.443 & 22700.8 & 11.4557 & $3.29 \mathrm{E}-05$ \\
\hline \multirow{5}{*}{2} & 15000 & 0 & 0.2 & 5.1 & 1.5 & 44.5206 & 0.2 & 1031.4 & 1.7 & 3000.825 & 25846.4 & 11.718 & $1.99 \mathrm{E}-04$ \\
\hline & 60 & 100 & 0.3 & 20.8 & 1 & 17.1419 & 0.4 & 1495.5 & 4.3 & 2876.971 & 26149.6 & 12.7133 & $2.03 \mathrm{E}-04$ \\
\hline & 60 & 300 & 0.2 & 0.9 & 1.1 & 11.2548 & 0.2 & 1044.5 & 6.4 & 2846.976 & 29773.7 & 10.502 & $2.56 \mathrm{E}-04$ \\
\hline & 90 & 100 & 0.2 & 29.6 & 1.1 & 28.00728 & 0.5 & 3463.6 & 2.9 & 2783.035 & 16136.5 & 12.8753 & $1.86 \mathrm{E}-05$ \\
\hline & 90 & 300 & 0.2 & 2.6 & 0.9 & 7.5621 & 0.1 & 971.2 & 6.6 & 2627.616 & 22788.8 & 10.112 & $1.40 \mathrm{E}-04$ \\
\hline \multirow{5}{*}{3} & 15000 & 0 & 0.3 & 42.2 & 2 & 42.1322 & 0.4 & 1489.4 & 0.5 & 3008.248 & 29716 & 10.87798 & $7.28 \mathrm{E}-04$ \\
\hline & 60 & 100 & 0.1 & 0 & 2 & 24.9994 & 0 & 3987.8 & 3 & 3342.277 & 66792.3 & 11.489 & $2.79 \mathrm{E}-04$ \\
\hline & 60 & 300 & 0.5 & 1.2 & 2 & 20.28246 & 0.1 & 2467.8 & 9.6 & 3061.365 & 43941.6 & 7.9404 & $4.17 \mathrm{E}-04$ \\
\hline & 90 & 100 & 1.2 & 0.7 & 2 & 46.4146 & 0.1 & 5956.4 & 1.4 & 3142.13 & 38236.9 & 9.2584 & $1.46 \mathrm{E}-04$ \\
\hline & 90 & 300 & 0.5 & 2.2 & 2 & 38.7482 & 0.2 & 2499.6 & 8.3 & 2769.62 & 39654 & 8.7365 & $1.39 \mathrm{E}-04$ \\
\hline \multirow{5}{*}{4} & 15000 & 0 & 0.2 & 16 & 2 & 47.6986 & 0.5 & 986.2 & 0 & 2915.261 & 7055.8 & 6.858 & $2.17 \mathrm{E}-04$ \\
\hline & 60 & 100 & 0.3 & 13.8 & 2 & 30.2494 & 0.4 & 2930.6 & 1.3 & 3502.799 & 26376.4 & 10.5744 & $2.45 \mathrm{E}-04$ \\
\hline & 60 & 300 & 0.5 & 45 & 2 & 33.149 & 0.8 & 2530.6 & 5.4 & 3343.474 & 24974.8 & 11.48994 & $3.33 \mathrm{E}-04$ \\
\hline & 90 & 100 & 1 & 20.2 & 2 & 41.8831 & 0.5 & 4953.5 & 0.7 & 3085.512 & 11005.2 & 9.2545 & $2.32 \mathrm{E}-05$ \\
\hline & 90 & 300 & 0.2 & 32.6 & 1.9 & 50.2826 & 0.5 & 998.3 & 6.4 & 2928.979 & 24122.4 & 9.0995 & $1.34 \mathrm{E}-04$ \\
\hline \multirow{5}{*}{5} & 15000 & 0 & 0.6 & 1.1 & 0.2 & 58.1624 & 0.1 & 2933.9 & 0.8 & 3073.144 & 23107.8 & 9.4294 & $4.51 \mathrm{E}-04$ \\
\hline & 60 & 100 & 0.8 & 6.8 & 0 & 22.7375 & 0.1 & 3938.5 & 5.6 & 3324.167 & 44578 & 12.934 & $1.24 \mathrm{E}-04$ \\
\hline & 60 & 300 & 0.4 & 15.5 & 0.2 & 24.6497 & 0.3 & 1999.6 & 7.6 & 3375.375 & 56762.2 & 11.5463 & $1.90 \mathrm{E}-04$ \\
\hline & 90 & 100 & 1 & 0 & 0.1 & 25.0875 & 0 & 5013 & 3.5 & 3190.673 & 36963.3 & 10.88335 & $9.15 \mathrm{E}-05$ \\
\hline & 90 & 300 & 0.2 & 5.6 & 0 & 23 & 0.1 & 2005.9 & 7.9 & 3106.396 & 36820.4 & 12.0768 & $7.31 \mathrm{E}-05$ \\
\hline \multirow{5}{*}{6} & 15000 & 0 & 0.5 & 21.8 & 1.1 & 63.6563 & 0.3 & 2419.8 & 1 & 3496.847 & 45124.3 & 14.2877 & $1.44 \mathrm{E}-04$ \\
\hline & 60 & 100 & 0.6 & 6 & 1 & 32.1421 & 0.3 & 3064.8 & 3 & 3532.152 & 49716.9 & 14.01048 & $1.77 \mathrm{E}-04$ \\
\hline & 60 & 300 & 0.3 & 3.1 & 0.9 & 33.0421 & 0.2 & 1532.1 & 8.9 & 3178.958 & 42986.1 & 12.1122 & $2.99 \mathrm{E}-04$ \\
\hline & 90 & 100 & 0.1 & 28.2 & 1.1 & 46.12489 & 0.5 & 5415.5 & 2.1 & 3143.474 & 36277.1 & 11.9657 & $6.86 \mathrm{E}-05$ \\
\hline & 90 & 300 & 0.5 & 8.6 & 1.2 & 50.2707 & 0.4 & 2506.3 & 8.4 & 2986.309 & 35778.3 & 9.2503 & $3.11 \mathrm{E}-05$ \\
\hline \multirow{5}{*}{7} & 15000 & 0 & 0.3 & 18.8 & 1 & 43.5414 & 0.8 & 1538.3 & 1.3 & 2758.248 & 10467 & 9.5427 & $1.43 \mathrm{E}-04$ \\
\hline & 60 & 100 & 0.2 & 15.7 & 1 & 14.01399 & 0.4 & 3435.2 & 3.5 & 3381.961 & 50912.3 & 10.6997 & $1.88 \mathrm{E}-04$ \\
\hline & 60 & 300 & 0.5 & 3.7 & 1 & 9.3279 & 0.2 & 2483.5 & 8.5 & 3259.839 & 43868 & 9.7731 & $2.92 \mathrm{E}-04$ \\
\hline & 90 & 100 & 0.1 & 7.3 & 1 & 20.78463 & 0.4 & 4990.2 & 1.8 & 3150.072 & 33034.4 & 9.4066 & $1.53 \mathrm{E}-05$ \\
\hline & 90 & 300 & 0.4 & 24.1 & 1.2 & 17.93 & 0.4 & 2025.3 & 7.9 & 2809.2 & 38133 & 8.9339 & $3.01 \mathrm{E}-04$ \\
\hline
\end{tabular}

${ }^{1}$ PBIMI is the predefined BIM interval in the second method (the BIMs interval adjustment method),

the level 15000 is used for referring to first method (ordinary scheduling);

${ }^{2}$ MST is the Mean Surgery Time for emergency surgeries in the second method (the BIMs interval adjustment method), the level 0 is used for referring to first method (ordinary scheduling);

${ }^{3}$ NEmgL or the Number of Emergencies that are scheduled with lateness;

${ }^{4}$ SLEmg or the Summation of Lateness in Emergencies;

${ }^{5}$ NUnEmg or the Number of Unscheduled Emergencies in ordinary time that are scheduled in the overtime;

${ }^{6}$ AWTEmg or Average Waiting Time in Emergencies;

${ }^{7}$ NElecL or the Number of Electives that are scheduled with Lateness;

${ }^{8}$ SLElec or the Summation of Lateness in Electives;

${ }^{9}$ NUnElec or the Number of Unscheduled Electives;

${ }^{10}$ AWTElec or Average Waiting Time in Electives;

${ }^{11} \mathrm{Un}$-stability is the summation of the violation of start times of electives in the final schedule

(after inserting all the emergencies) from their start times in initial schedule (without any emergencies);

${ }^{12}$ VORL or 'Violation from OR Leveling' is the difference between the maximum and minimum percentage of

the OR usage among various ORs. 
Table 5. The mean value table.

\begin{tabular}{|c|c|c|c|c|c|c|c|c|c|c|c|c|c|}
\hline \multirow[b]{2}{*}{ PBIMI } & \multirow[b]{2}{*}{ MST } & \multirow[b]{2}{*}{$\begin{array}{c}\text { Number of } \\
\text { observations }\end{array}$} & \multicolumn{11}{|c|}{ Mean of response variables } \\
\hline & & & 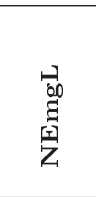 & 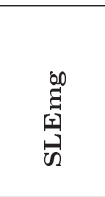 & 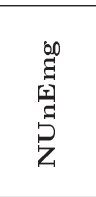 & 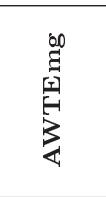 & $\frac{-1}{0}$ & 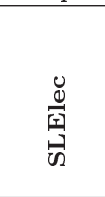 & 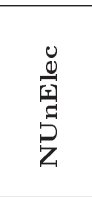 & 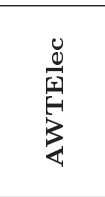 & 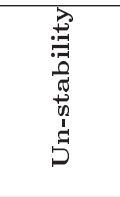 & $\begin{array}{l}-1 \\
0 \\
0 \\
0\end{array}$ & 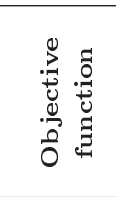 \\
\hline 1500 & 0 & 7 & 0.3286 & 19.4286 & 1.3571 & 50.5948 & 0.4714 & 1631.44 & 0.8143 & 3030.94 & 22998.80 & 10.5871 & $2.97 \mathrm{E}-04$ \\
\hline 60 & - & 14 & 0.4071 & 12.1071 & 1.2429 & 24.0784 & 0.3071 & 2561.29 & 5.4286 & 3254.91 & 39505.05 & 11.3463 & $2.53 \mathrm{E}-04$ \\
\hline 90 & - & 14 & 0.4929 & 14.1643 & 1.2857 & 34.4632 & 0.3500 & 3377.31 & 4.7143 & 2978.43 & 28947.98 & 10.3369 & $8.84 \mathrm{E}-05$ \\
\hline- & 100 & 14 & 0.5357 & 12.4214 & 1.2857 & 29.8746 & 0.3214 & 4042.57 & 2.5643 & 3200.77 & 33559.10 & 11.4211 & $1.31 \mathrm{E}-04$ \\
\hline - & 300 & 14 & 0.3643 & 13.8500 & 1.2429 & 28.6670 & 0.3357 & 1896.02 & 7.5786 & 3032.57 & 34893.93 & 10.2622 & $2.10 \mathrm{E}-04$ \\
\hline
\end{tabular}

Table 6. Factorial ANOVA for NEMGL.

\begin{tabular}{lccccc}
\hline \multicolumn{1}{c}{ Source } & DF & SS & MS & F & P \\
\hline PBIMI & 1 & 0.0514 & 0.0514 & 0.70 & 0.4105 \\
MST & 1 & 0.2057 & 0.2057 & 2.79 & 0.1054 \\
PBIMI* & 1 & 0.1729 & 0.1729 & 2.34 & 0.1364 \\
MST & & & & & \\
Error & 30 & 2.2143 & 0.0738 & & \\
Total & 34 & 2.7269 & & & \\
\hline
\end{tabular}

Table 7. Factorial ANOVA for SLEmg.

\begin{tabular}{lccccc}
\hline Source & DF & SS & MS & F & P \\
\hline PBIMI & 1 & 29.62 & 29.62 & 0.18 & 0.6755 \\
MST & 1 & 14.29 & 14.29 & 0.09 & 0.7711 \\
PBIMI* $^{*}$ & 1 & 4.32 & 4.32 & 0.03 & 0.8728 \\
MST & & & & & \\
Error & 30 & 4974.35 & 165.81 & & \\
Total & 34 & 5244.34 & & & \\
\hline
\end{tabular}

Table 8. Factorial ANOVA for NUnEmg.

\begin{tabular}{lccccc}
\hline Source & DF & SS & MS & F & P \\
\hline PBIMI & 1 & 0.0129 & 0.0129 & 0.03 & 0.8687 \\
MST & 1 & 0.0129 & 0.0129 & 0.03 & 0.8687 \\
PBIMI* & 1 & 0.0014 & 0.0014 & 0.00 & 0.9560 \\
MST & & & & & \\
Error & 30 & 13.8743 & 0.4625 & & \\
Total & 34 & 13.9497 & & & \\
\hline
\end{tabular}

Table 9. Factorial ANOVA for AWTEmg.

\begin{tabular}{lccccc}
\hline Source & DF & SS & MS & F & P \\
\hline PBIMI & 1 & 754.907 & 754.91 & 5.90 & 0.0214 \\
MST & 1 & 10.208 & 10.21 & 0.08 & 0.7796 \\
PBIMI* & 1 & 14.173 & 14.17 & 0.11 & 0.7416 \\
MST & & & & & \\
Error & 30 & 3840.35 & 128.01 & & \\
Total & 34 & 7166.03 & & & \\
\hline
\end{tabular}

This section examines the efficiency of the ordinary method (the first method) and the BIMs interval adjustment method (the second method) using a number of experiments based on real data.

In the case of the quality measurements related to the emergency surgeries, the second method is preferable because both methods achieve similar results in ' $N E m g L$ ', 'NUnEmg', and 'SLEmg', but the second method decreases 'AWTEmg'. However, by considering quality measurements related to the elective surgeries, the first method outperforms the second method. Both methods have similar results in 'NElecL', but the first method gives better results in 'NUnElec' and then, in the second method, the level 100 of the 'MST' effect acts somewhat better than level 300 in this quality measurement. In 'AWTElec' quality measurement, the second method gives the worst results when the 'PBIMI' effect is at a level of 60 , but the difference between the level 90 (in the second method) and level 15000 (the first method) of the 'PBIMI' effect is not statistically significant.

Moreover, in the 'Un-stability' quality measurement, level 60 of the 'PBIMI' effect gives the worst results for 'Un-stability', but there is no significant difference between the first method and the second method when 'PBIMI' is at the level 90. In the case of ' $V O R L$ ' quality measurement, both methods achieve similar results.

Finally, the best value for 'Objective Function' is related to the level 90 of the 'PBIMI' effect in the second method. Table 23 gives a summary of the comparison between two methods according to various quality measurements.

The analysis results show that our proposed algorithm for the BIMs interval adjustment is more preferable than the ordinary method of scheduling elective surgeries. For this reason, decreasing the average waiting time in emergency surgeries and having equivalent performance in other quality measurements for related to emergency surgeries are achieved. Our proposed algorithm for the BIMs interval adjustment gives a better objective function when 'PBIMI' is at level 90. Generally, when 'PBIMI' is at level 90 and 'MST' is at level 100, the BIMs interval adjustment has a better or similar performance in many of our quality measurements.

\section{Conclusion and future works}

This study proposed the Scheduling Elective and Emergency Surgery (SEES) algorithm, which is an improved 
Table 10. Tukey (HSD) test for 'AWTEmg'.

\begin{tabular}{lcccc}
\hline Alpha & & & 0.05 \\
Error DF & & & 30 \\
Error MS & & & 128.01 \\
Critical value of studentized range & & \multicolumn{3}{c}{3.49} \\
\hline \multicolumn{1}{c}{ PBIMI } & Difference & \multicolumn{2}{c}{ Simultaneous $95 \%$} & \\
comparison & between means & Confidence limits & \\
\hline $15000-90$ & 16.132 & 3.22 & 29.043 & $* * *$ \\
$15000-60$ & 26.516 & 13.605 & 39.428 & $* * *$ \\
$90-15000$ & -16.132 & -29.043 & -3.22 & $* * *$ \\
$90-60$ & 10.385 & -0.158 & 20.927 & \\
$60-15000$ & -26.516 & -39.428 & -13.605 & $* * *$ \\
$60-90$ & -10.385 & -20.927 & 0.158 & \\
\hline
\end{tabular}

Note: Comparisons significant at the 0.05 level are indicated by ***.

Table 11. Factorial ANOVA for NElecL.

\begin{tabular}{lccccc}
\hline Source & DF & SS & MS & F & P \\
\hline PBIMI & 1 & 0.0129 & 0.0129 & 0.22 & 0.6404 \\
MST & 1 & 0.0014 & 0.0014 & 0.02 & 0.8760 \\
PBIMI* & 1 & 0.0057 & 0.0057 & 0.1 & 0.7552 \\
MST & & & & & \\
Error & 30 & 1.7314 & 0.0577 & & \\
Total & 34 & 1.8657 & & & \\
\hline
\end{tabular}

Table 12. Factorial ANOVA for SLElec.

\begin{tabular}{lccccc}
\hline \multicolumn{1}{c}{ Source } & DF & SS & MS & F & P \\
\hline PBIMI & 1 & $4.7 \mathrm{E}+06$ & $4.7 \mathrm{E}+06$ & 9.0 & 0.0054 \\
MST & 1 & $3.2 \mathrm{E}+07$ & $3.2 \mathrm{E}+07$ & 62.3 & 0.0001 \\
PBIMI $^{*}$ & 1 & $7.5 \mathrm{E}+06$ & $7.5 \mathrm{E}+06$ & 14.5 & 0.0006 \\
MST & & & & & \\
Error & 30 & $1.6 \mathrm{E}+07$ & $5.2 \mathrm{E}+05$ & & \\
Total & 34 & $7.0 \mathrm{E}+07$ & & & \\
\hline
\end{tabular}

Table 13. Factorial ANOVA for NUnElec.

\begin{tabular}{lccccc}
\hline Source & DF & SS & MS & F & P \\
\hline PBIMI & 1 & 3.57 & 3.57 & 2.84 & 0.1025 \\
MST & 1 & 176.00 & 176.00 & 140 & 0.0001 \\
PBIMI* & 1 & 2.40 & 2.40 & 1.91 & 0.1775 \\
MST & & & & & \\
Error & 30 & 37.77 & 1.26 & & \\
Total & 34 & 321.24 & & & \\
\hline
\end{tabular}

constructive meta-heuristic algorithm, for SEES. The SEES algorithm is an extension of the Generalized Operational Surgery-Scheduling Problem (OGOSSP) algorithm by including the scheduling of emergency surgeries and developing the idea of the Break-In-
Table 14. Factorial ANOVA for AWTElec.

\begin{tabular}{lccccc}
\hline Source & DF & SS & MS & F & P \\
\hline PBIMI & 1 & 535076 & 535076 & 15.2 & 0.0005 \\
MST & 1 & 198023 & 198023 & 5.63 & 0.0243 \\
PBIMI* & 1 & 3823 & 3823 & 0.11 & 0.7440 \\
MST & & & & & \\
Error & 30 & 1055352 & 35178 & & \\
Total & 34 & 1833432 & & & \\
\hline
\end{tabular}

Moments (BIMs) interval adjustment in the Operating Rooms (ORs). Our main contribution is implementing the BIMs interval adjustment in scheduling elective surgeries when surgeries are projects with multi-mode activities. To the best of our knowledge, in all previous works done on the BIMs interval adjustment, the duration of using the OR had a determined value. Moreover, the set of elective surgeries in any OR was given. Despite the previous literature on the BIMs interval adjustment, here, we assumed that the algorithm determined which elective surgeries would be assigned to each OR. Moreover, surgery activity has multiple modes; thus, its duration depends on the selected mode during the execution of the algorithm.

To investigate the efficiency of this algorithm, two methods of scheduling elective surgeries were considered: the ordinary method and the BIMs interval adjustment method. Then, some experiments for inserting the emergency surgeries into these two schedules were examined and various quality measurements were compared. The results of the analysis demonstrated that our algorithm achieved better performance in quality measurements related to emergency surgeries. This algorithm managed to reduce the average waiting time in emergency surgeries and our algorithm gave a better objective function at some levels of the main factors. However, in the case of quality measurements 
Table 15. Tukey (HSD) test for 'NUnElec'.

\begin{tabular}{lcccc}
\hline Alpha & & & & 0.05 \\
Error DF & & & 30 \\
Error MS & & & 1.26 \\
Critical value of studentized range & & & 3.49 \\
\hline PBIMI & Difference & Simultaneous $95 \%$ & \\
comparison & between means & Confidence limits & \\
\hline $100-300$ & -5.0143 & -6.0598 & -3.9688 & $* * *$ \\
$100-0$ & 1.7500 & 0.4695 & 3.0305 & $* * *$ \\
$300-100$ & 5.0143 & 3.9688 & 6.0598 & $* * *$ \\
$300-0$ & 6.7643 & 5.4838 & 8.0448 & $* * *$ \\
$0-100$ & -1.7500 & -3.0305 & -0.4695 & $* * *$ \\
$0-300$ & -6.7643 & -8.0448 & -5.4838 & $* * *$ \\
\hline
\end{tabular}

Note: Comparisons significant at the 0.05 level are indicated by ***.

Table 16. Tukey (HSD) test for 'AWTElec' (PBIMI).

\begin{tabular}{lcccc}
\hline Alpha & & & & 0.05 \\
Error DF & & & 30 \\
Error MS & & & 35178.39 \\
Critical value of studentized range & & & 3.49 \\
\hline \multicolumn{1}{c}{ PBIMI } & Difference & Simultaneous $95 \%$ & \\
comparison & between means & Confidence limits & \\
\hline $15000-90$ & 52.51 & -161.53 & 266.55 & \\
$15000-60$ & -223.97 & -438.01 & -9.93 & $* * *$ \\
$90-15000$ & -52.51 & -266.55 & 161.53 & \\
$90-60$ & -276.48 & -451.24 & -101.71 & $* * *$ \\
$60-15000$ & 223.97 & 9.93 & 438.01 & $* * *$ \\
$60-90$ & 276.48 & 101.71 & 451.24 & $* * *$ \\
\hline
\end{tabular}

Note: Comparisons significant at the 0.05 level are indicated by $* * *$.

Table 17. Tukey (HSD) test for 'AWTElec' (MST).

\begin{tabular}{lccc}
\hline Alpha & & 0.05 \\
Error DF & & 30 \\
Error MS & & 35178.39 \\
Critical value of studentized range & & 3.49 \\
\hline PBIMI & Difference & Simultaneous $95 \%$ \\
comparison & between means & Confidence limits \\
\hline $100-300$ & 168.19 & -6.57 & 342.96 \\
$100-0$ & 169.83 & -44.21 & 383.87 \\
$300-100$ & -168.19 & -342.96 & 6.57 \\
$300-0$ & 1.63 & -212.41 & 215.68 \\
$0-100$ & -169.83 & -383.87 & 44.21 \\
$0-300$ & -1.63 & -215.68 & 212.41 \\
\hline
\end{tabular}


Table 18. Factorial ANOVA for Un-stability.

\begin{tabular}{lccccc}
\hline Source & DF & SS & MS & F & P \\
\hline PBIMI & 1 & $7.8 \mathrm{E}+08$ & $7.8 \mathrm{E}+08$ & 4.90 & 0.0346 \\
MST & 1 & $1.3 \mathrm{E}+07$ & $1.3 \mathrm{E}+07$ & 0.08 & 0.7815 \\
PBIMI* $^{*}$ & 1 & $9.2 \mathrm{E}+07$ & $9.2 \mathrm{E}+07$ & 0.58 & 0.4530 \\
MST & & & & & \\
Error & 30 & $4.8 \mathrm{E}+09$ & $1.6 \mathrm{E}+08$ & & \\
Total & 34 & $6.4 \mathrm{E}+09$ & & & \\
\hline
\end{tabular}

Table 19. Factorial ANOVA for VORL.

\begin{tabular}{lccccc}
\hline \multicolumn{1}{c}{ Source } & DF & SS & MS & F & P \\
\hline PBIMI & 1 & 7.1322 & 7.1322 & 2.8 & 0.1049 \\
MST & 1 & 9.4016 & 9.4016 & 3.69 & 0.0644 \\
PBIMI* & 1 & 1.0607 & 1.0607 & 0.42 & 0.5239 \\
MST & & & & & \\
Error & 30 & 76.5122 & 2.5504 & & \\
Total & 34 & 94.4694 & & & \\
\hline
\end{tabular}

related to elective surgeries, the ordinary method achieved better results.

The most important point of our proposed algorithm is the ability to decrease the average waiting time in emergency surgeries without dedicating any OR to emergency surgeries while having a good performance in the objective function. Generally, the proposed algorithm in this paper is appropriate for OR departments with the following specifications: expensive surgeries, normal rate of emergency arrivals, and patients that can afford some waiting time.

The problem of scheduling surgeries at the operational level is dealt with in this paper. The structure of the proposed algorithm allows us to treat all the
Table 21. Factorial ANOVA for 'Objective Function'.

\begin{tabular}{lccccc}
\hline Source & DF & SS & MS & F & P \\
\hline PBIMI & 1 & $1.90 \mathrm{E}-07$ & $1.90 \mathrm{E}-07$ & 14.5 & 0.0007 \\
MST & 1 & $4.41 \mathrm{E}-08$ & $4.41 \mathrm{E}-08$ & 3.36 & 0.0768 \\
PBIMI* $^{*}$ & 1 & $1.15 \mathrm{E}-09$ & $1.15 \mathrm{E}-09$ & 0.09 & 0.7690 \\
MST & & & & & \\
Error & 30 & $3.94 \mathrm{E}-07$ & $1.31 \mathrm{E}-08$ & & \\
Total & 34 & $7.18 \mathrm{E}-07$ & & & \\
\hline
\end{tabular}

resource types as homogeneous entities that have some availability intervals with some capacities. Nurses are one of the resources and their availability comes from the nurse rostering problem. This is a complicated problem because it requires considering many nursing specifications including skills, qualifications, attentiveness to shift preferences, and contractual agreements. There are many papers on this issue in the literature. The nurse rostering problem and the Surgery Scheduling Problem (SSP) are two interrelated problems, but a few papers have dealt with these problems in a synchronous manner. We suggest an extension of our work by integrating it with the nurse rostering problem for future research.

In this paper, we supposed that the information of the OR time blocks that determined the availability of ORs for each surgery specialty was given. These OR time blocks have a real impact on the quality of the schedules in the SSP. We also suggest the integration of our work with the problem of determination of the OR time blocks for future works.

After surgery, patients need to access some postoperative care resources. Recovery rooms, ward beds, and Intensive Care Units (ICUs) are important downstream resources. These resources are the bottleneck

Table 20. Tukey (HSD) test for 'Un-stability'.

\begin{tabular}{lcccc}
\hline Alpha & & \multicolumn{2}{c}{0.05} \\
Error DF & & 30 & \\
Error MS & & \multicolumn{3}{c}{$1.6 \mathrm{E}+08$} \\
Critical value of studentized range & & \multicolumn{4}{c}{3.49} & \\
\hline \multicolumn{1}{c}{ PBIMI } & Difference & Simultaneous $95 \%$ & \\
comparison & between means & Confidence limits & \\
\hline $15000-90$ & -5949 & -20349 & 8450 & \\
$15000-60$ & -16506 & -30906 & -2107 & $* * *$ \\
$90-15000$ & 5949 & -8450 & 20349 & \\
$90-60$ & -10557 & -22314 & 1200 & \\
$60-15000$ & 16506 & 2107 & 30906 & $* * *$ \\
$60-90$ & 10557 & -1200 & 22314 & \\
\hline
\end{tabular}

Note: Comparisons significant at the 0.05 level are indicated by $* * *$. 
Table 22. Tukey (HSD) test for 'Objective Function'.

\begin{tabular}{lcccc}
\hline $\begin{array}{l}\text { Alpha } \\
\text { Error DF }\end{array}$ & & & 0.05 \\
Error MS & & & 30 \\
Critical value of studentized range & & & $1.31 \mathrm{E}-08$ \\
\hline \multicolumn{1}{c}{ PBIMI } & Difference & \multicolumn{2}{c}{ Simultaneous $95 \%$} & 3.49 \\
comparison & between means & Confidence limits & \\
\hline $15000-90$ & $2.0848 \mathrm{E}-04$ & $7.8 \mathrm{E}-05$ & 0.00034 & $* * *$ \\
$15000-60$ & $4.3870 \mathrm{E}-05$ & $-8.7 \mathrm{E}-05$ & 0.00017 & \\
$90-15000$ & $-2.0848 \mathrm{E}-04$ & -0.00034 & $-7.8 \mathrm{E}-05$ & $* * *$ \\
$90-60$ & $-1.6461 \mathrm{E}-04$ & -0.00027 & $-5.8 \mathrm{E}-05$ & $* * *$ \\
$60-15000$ & $-4.3870 \mathrm{E}-05$ & -0.00017 & $8.7 \mathrm{E}-05$ & \\
$60-90$ & $1.6461 \mathrm{E}-04$ & $5.8 \mathrm{E}-05$ & 0.00027 & $* * *$ \\
\hline
\end{tabular}

Note: Comparisons significant at the 0.05 level are indicated by ***.

Table 23. The results of the comparisons between two methods in quality measurements.

\begin{tabular}{|c|c|c|}
\hline & $\begin{array}{c}\text { Quality } \\
\text { measurement }\end{array}$ & Comparison result \\
\hline \multirow{4}{*}{ 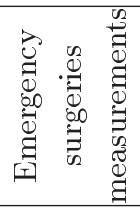 } & NEmgL & Both methods act similarly \\
\hline & SLEmg & Both methods act similarly \\
\hline & NUnEmg & Both methods act similarly \\
\hline & AWTEmg & The BIMs interval adjustment method acts better \\
\hline \multirow{5}{*}{ 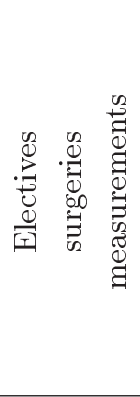 } & NElecL & Both methods act similarly \\
\hline & SLElec & $\begin{array}{l}\text { The main factors and their interaction are statistically significant } \\
\text { It is difficult to judge which method is better }\end{array}$ \\
\hline & NInFler & The ordinary method acts better, but in the case of the \\
\hline & & BIMs interval adjustment method, level 100 is preferable to level 300 in MST \\
\hline & AWTElec & $\begin{array}{l}\text { The ordinary method acts similarly to the BIMs interval } \\
\text { adjustment method when PBIMI is at the level of } 90 \text {. Both of } \\
\text { these act better than level } 60 \text { in PBIMI in the BIMs interval adjustment method }\end{array}$ \\
\hline \multirow[t]{3}{*}{ 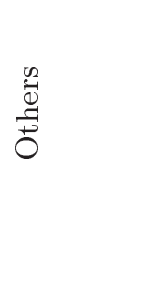 } & Un-stability & $\begin{array}{l}\text { The ordinary method acts similarly to the BIMs interval } \\
\text { adjustment method when PBIMI is at a level of } 90 \text {. Both of } \\
\text { them act better than level } 60 \text { in PBIMI in the BIMs interval adjustment method }\end{array}$ \\
\hline & VORL & Both methods act similarly \\
\hline & Objective function & $\begin{array}{l}\text { The BIMs interval adjustment method has the best result } \\
\text { when PBIMI is at a level of } 90\end{array}$ \\
\hline
\end{tabular}

resources of the surgery-scheduling problem because their unavailability can cause schedule disruption and cancellation of elective surgeries and other difficulties. As for future work, we suggest the integration of our work with the problem of determining the optimum capacity of important downstream resources.

\section{References}

1. Cardoen, B., Demeulemeester, E., and Beliën, J. "Operating room planning and scheduling: a literature review", Eur. J. Oper. Res., 201(3), pp. 921-932 (2010).

2. May, J., Spangler, W., Strum, D., et al. "The surgical scheduling problem: current research and future opportunities", Production and Operations Management, 20(3), pp. 392-405 (2011).

3. Zhu, S., Fan, W., Yang, S., et al. "Operating room planning and surgical case scheduling: a review of literature", Journal of Combinatorial Optimization, 37, pp. 757-805 (2019). https://doi.org/10.1007/s10878$018-0322-6$ 
4. Guerriero, F. and Guido, R. "Operational research in the management of the operating theatre: a survey", Health Care Management Science, 14(1), pp. 89-114 (2011).

5. Duma, D. and Aringhieri, R. "An online optimization approach for the Real Time Management of operating rooms", Operations Research for Health Care, 7, pp. 40-51 (2015).

6. Litvak, N., Rijsbergen, M., Boucherie, R., et al. "Managing the overflow of intensive care patients", European Journal of Operation Research, 185(3), pp. 998-1010 (2008).

7. Cardoen, B. and Demeulemeester, E. "On the use of planning models in the operating theater: Results of a survey in Flanders", The International Journal of Health Planning and Management, 25(4), pp. 400-414 (2010).

8. Erdogan, S.A. and Denton, B.T. "Surgery planning and scheduling", In Wiley Encyclopedia of Operations Research and Management Science, J.J. Cochran, L.A. Cox, P. Keskinocak, J.P. Kharoufeh, and J.C. Smith, Eds., John Wiley \& Sons (2010).

9. Ferrand, Y., Magazine, M., and Rao, U. "Managing operating room efficiency and responsiveness for emergency and elective surgeries-A literature survey", IIE Transactions on Healthcare Systems Engineering, 4, pp. 49-64 (2014).

10. Tancrez, J.S., Roland, B., Cordier, J., et al. "Assessing the impact of stochasticity for operating theater sizing", Decision Support Systems, 55(2), pp. 616-628 (2013).

11. Tancrez, J.S., Roland, B., Cordier, J., et al. "How stochasticity and emergencies disrupt the surgical schedule", Intelligent Patient Management, 189, pp. 221-239 (2009).

12. Van Riet, C. and Demeulemeester, E. "Trade-offs in operating room planning for electives and emergencies: A review", Operation Research for Health Care, 7, pp. 52-69 (2015).

13. Persson, M. and Persson, J.A. "Analyzing management policies for operating room planning using simulation", Health Care Management Science, 13(2), pp. 182-191 (2010).

14. Van Essen, J., Hans, E., Hurink, J., et al. "Minimizing the waiting time for emergency surgery", Operation Research Health Care, 1, pp. 34-44 (2012).

15. Vandenberghe, M., Vuyst, S., and Aghezzaf, E. "Surgery sequencing to minimize the expected maximum waiting time of emergent patients", European Journal of Operational Research, 275(3), pp. 971-982 (2019).

16. Duma, D. and Aringhieri, R. "The management of non-elective patients: shared vs. dedicated policies", Omega, 83, pp. 199-212 (2019).

17. Ferrand, Y., Magazine, M., and Rao, U. "Partially flexible operating rooms for elective and emergency surgeries", Decision Sciences, 45, pp. 819-847 (2014).
18. Samudra, M., Van Riet, C., Demeulemeester, E., et al. "Scheduling operating rooms: Achievements, challenges and pitfalls", Journal of Scheduling, 19(5), pp. $493-525$ (2016).

19. Gür, Ş. and Eren, T. "Application of operational research techniques in operating room scheduling problems: Literature overview", Journal of Healthcare Engineering, (2018). https://doi.org/10.1155/2018/5341394

20. Pham, D. and Klinkert, A. "Surgical case scheduling as a generalized job shop scheduling problem", European Journal of Operational Research, 185, pp. 1011-1025 (2008).

21. Van Essen, J., Hurink, J., Hartholt, W., et al. "Decision support system for the operating room rescheduling problem", Health Care Management Science, 15(4), pp. 355-372 (2012).

22. Jung, K., Pinedo, M., Sriskandarajah C., et al. "Scheduling elective surgeries with emergency patients at shared operating rooms", Production and Operations Management, 28(6), pp. 1407-1430 (2019). https://doi.org/10. 1111/poms.12993

23. Aringhieri, R., Landa, P., Soriano, P., et al. "A twolevel metaheuristic for the operating room scheduling and assignment problem", Computers \& Operations Research, 54, pp. 21-34 (2015).

24. Moosavi, A. and Ebrahimnejad, S. "Scheduling of elective patients considering upstream and downstream units and emergency demand using robust optimization", Computers \& Industrial Engineering, 120, pp. 216-233 (2018).

25. Riise, A., Mannino, C., and Burke, E.K. "Modelling and solving generalized operational surgery scheduling problems", Computers and Operations Research, 66, pp. 1-11 (2016).

26. Hans, E., Wullink, G., van Houdenhoven, M., et al. "Robust surgery loading", European Journal of Operational Research, 185(3), pp. 1038-1050 (2008).

27. Santibáñez, P., Begen, M., and Atkins, D. "Surgical block scheduling in a system of hospitals: an application to resource and wait list management in a British Columbia health authority", Health Care Manage Sci, 10, pp. 269-282 (2007).

28. Banditori, C., Cappanera, P., and Visintin, F. "A combined optimization-simulation approach to the master surgical scheduling problem", IMA Journal of Management Mathematics, 24, pp. 155-187 (2013).

29. Cappanera, P., Visintin, F., and Banditori, C. "Addressing conflicting stakeholders' priorities in surgical scheduling by goal programming", Flexible Services and Manufacturing Journal, 30, pp. 252-271 (2018).

30. Visintin, F., Cappanera, P., and Banditori, C. "Evaluating the impact of flexible practices on the master surgical scheduling process: an empirical analysis", Flexible Services and Manufacturing Journal, 28, pp. 182-205 (2016). 
31. Riise, A. and Mannino, C. "The surgery scheduling problem - a general model", Report SINTEF (2012).

32. Yazdi, M., Zandieh, M., and Haleh, H. "A mathematical model for scheduling elective surgeries for minimizing the waiting times in emergency surgeries", International Journal of Engineering, 33(3), pp. 448458 (2020).

33. St $\phi$ levik, M., Nordlander, T., and Riise, A., Nurse Rostering Test Cases, SINTEF ICT, Available at: https://www.sintef.no/Projectweb/Healthcare-optimizat ion/Testbed/, Accessed 3 November 2016.

34. Lamiri, M., Xie, X., Dolgui, A., et al. "A stochastic model for operating room planning with elective and emergency demand for surgery", European Journal of Operational Research, 185, pp. 1026-1037 (2008).

35. Bowers, J. and Mould, G. "Managing uncertainty in orthopedic trauma theatres", European Journal of Operational Research, 154(3), pp. 599-608 (2004).

\section{Biographies}

Maryam Yazdi is a PhD Candidate at the Department of Industrial Engineering, Faculty of Industrial and Mechanical Engineering, Qazvin Branch, Islamic Azad University, Qazvin, Iran. She received her BSc from Computer and IT Group of Department of Electrical \& Computer Engineering, Isfahan University of Technology, Isfahan, Iran. She obtained her MSc in the Industrial \& Systems Engineering Faculty Tarbiat Modares University, Tehran, Iran. Her research interests include scheduling, meta-heuristic algorithms, multi-objective optimization, and inventory management.
Mostafa Zandieh accomplished his BSc in Industrial Engineering at Amirkabir University of Technology, Tehran, Iran (1994-1998) and MSc in the same field at Sharif University of Technology, Tehran, Iran (19982000). He continued his studies in $\mathrm{PhD}$ program at Amirkabir University of Technology, Tehran, Iran (2000-2006). Currently, he is a Professor at Industrial Management and Information Technology Department, Shahid Beheshti University, Tehran, Iran. His research interests are production planning and scheduling, financial engineering, quality engineering, applied operations research, simulation, and artificial intelligence techniques in the areas of manufacturing systems design.

Hassan Haleh is an Assistant Professor of Industrial Engineering at Golpayegan University of Technology, Iran. He presently focuses his study on the areas of automated warehouses, supply chain, FMS, and CAD/CAM.

Seyed Hamid Reza Pasandideh is an Associate Professor at the Department of Industrial Engineering at the Kharazmi University, Tehran, Iran. He received his BSc, MSc, and PhD in Industrial Engineering from Sharif University of Technology, Tehran, Iran. Also, he conducted postdoctoral research on Cold Supply Chain at the University of Nebraska-Lincoln, Lincoln, US. His research interests include optimizing inventory control, multi-objective optimization, and application of queuing theory. He has published widely in those fields and is an editor in some journals such as International Journal of Supply and Operations Management (IJSOM). 